\title{
Assessing the Extent of Non-stationary Biases in GCMs
}

\author{
Jannatun Nahar ${ }^{1}$, Fiona Johnson ${ }^{1 *}$ and Ashish Sharma ${ }^{1}$ \\ ${ }^{1}$ School of Civil and Environmental Engineering, University of New South Wales, Sydney Australia
}

*Corresponding author's address:

Fiona Johnson, Water Research Centre, School of Civil and Environmental Engineering, University of New South Wales, Kensington, New South Wales, 2052, Australia.

E-mail: f.johnson@unsw.edu.au

Phone: +61293859769

Fax: +61293856139 


\section{Abstract}

General circulation models (GCMs) are the main tools for estimating changes in the climate for the future. The imperfect representation of climate models introduces biases in the simulations that need to be corrected prior to their use for impact assessments. Bias correction methods generally assume that the bias calculated over the historical period does not change and can be applied to the future. This study investigates this assumption by considering the extent and nature of bias nonstationarity using $20^{\text {th }}$ century precipitation and temperature simulations from six CMIP5 GCMs across Australia. Four statistics (mean, standard deviation, $10^{\text {th }}$ and $90^{\text {th }}$ quantiles) in monthly and seasonal biases are obtained for three different time window lengths (10, 25 and 33 years) to examine the properties of bias over time. This approach is repeated for two different phases of the Interdecadal Pacific Oscillation (IPO), which is known to have strong influences on the Australian climate. It is found that bias non-stationarity at decadal timescales is indeed an issue over some of Australia for some GCMs. When considering interdecadal variability there are significant difference in the bias between positive and negative phases of the IPO. Regional analyses confirmed these findings with the largest differences seen on the east coast of Australia, where IPO impacts tend to be the strongest. The nature of the bias non-stationarity found in this study suggests that it will be difficult to modify existing bias correction approaches to account for non-stationary biases. A more practical approach for impact assessments that use bias correction maybe to use a selection of GCMs where the assumption of bias non-stationarity holds.

Keywords: GCM bias; bias non-stationarity; inter-decadal variability 


\section{Introduction}

Anthropogenic climate change is leading to widespread impacts on human and natural systems (IPCC, 2014). Observations show that many key indicators of climate have shifted beyond the patterns of their natural variability due to the growth of contemporary society and economy (Richardson et al., 2009). Understanding how these changes might impact society and the economy in the future is vitally important ( $\mathrm{Li}$ et al., 2010). General circulation models (GCMs) are the main tools used to assess possible future scenarios of change and the impacts of these changes. Evaluation of these climate models against observations is important prior to their use in impact assessment (Perkins et al., 2007). GCMs have been found to show good skill in representing some variables of our climate system like pressure and temperature (Johnson and Sharma, 2009) and some features of rainfall (Perkins et al., 2007). However all models are imperfect representations of reality and GCMs are no exception, with a range of biases found between climate model simulations and observations (Maraun, 2012).

The term climate model bias is frequently used in climate change and impact research. Climate models have errors that consists of unsystematic and systematic components (Teutschbein and Seibert, 2013). Random or unsystematic model errors occur because of the chaotic nature of the climate system and the fact that the GCMs are not constrained to match the observations, and have their own dynamic feedback processes (Christensen et al., 2001). Eden et al. (2012) describe this as a Type 2 error but note that it is not an error in the traditional sense because it is the result of unconstrained nature of the GCM simulations. These random errors causes differences between the GCM and observations at time scales ranging from daily to annual (Eden et al., 2012). Hawkins and Sutton (2011) showed that the initial conditions and the chaotic nature of the climate system dominate climate model uncertainty for periods up to 5-10 years. The second type of error is the systematic error component that is commonly termed model bias (Teutschbein and Seibert, 2012b). These model errors are important contributions to uncertainty at decadal and multi-decadal time 
scales (Hawkins and Sutton, 2011). Possible causes of these biases are summarised by Maurer et al. (2013) and include the coarse scale of the GCMs, incomplete model structures, feedback loops including the albedo and land-atmosphere interactions and in the case of precipitation the parameterisation of clouds and convection. (Allen et al., 2002; Haerter et al., 2011; Masson and Knutti, 2011; Randall et al., 2007; Sun et al., 2006). To address these biases prior to impact assessments, a number of bias correction methods have been developed. These methods assume that if the biases can removed from the model simulations, then the corrected GCM outputs will properly represent the expected future changes in the climate system.

Compared to other approaches, bias correction has several advantages from the user's perspective. Bias correction is used directly on climate model output and, therefore the development and application of these methods does not require full access to the driving climate model simulations (Li et al., 2010). Moreover, bias correction is easy to apply and is flexible enough to correct the GCM simulations for the parameters of interest (Johnson and Sharma, 2012). Bias correction can also potentially improve the climate change signal (Gobiet et al., 2015) for example by increasing the model consensus on the direction of future changes (Johnson and Sharma, 2015). A number of different bias correction techniques have been proposed and applied (Boberg and Christensen, 2012; Buser et al., 2009; Christensen et al., 2008; Ho et al., 2012; Johnson and Sharma, 2012; Maraun, 2012; Mehrotra and Sharma, 2015; Piani et al., 2010; Wood et al., 2004).

Although bias correction has a number of benefits, there remains a belief in some quarters that bias correction lacks a sound physical basis (Ehret et al., 2012) because it does not necessarily preserve the dynamic relationships between different variables (Haerter et al., 2011). Therefore, some studies prefer to use dynamically downscaled model simulations for impact assessments (Ehret et al., 2012). It has also been suggested that bias correction can alter the climate change signal which in some cases is considered undesirable (Hagemann et al., 2011) and in others is considered beneficial (Gobiet et al., 2015). In some regions projected precipitation changes are significantly 
correlated with the biases (Giorgi and Coppola, 2010). In these cases, bias correction may introduce another level of uncertainty.

The major question in bias correction is how biases should be extrapolated into the future (Kerkhoff et al., 2014). This question is normally avoided by assuming that the bias is time invariant (Buser et al., 2009; Maraun, 2012). This assumption of bias stationarity implies that the bias statistics that are calculated over the historical period can simply be applied to the future simulations.

Support for the validity of bias correction approaches was provided by Macadam et al. (2010), who compared the ranking of GCMs on their ability to reproduce near surface temperatures and found that the rankings were not strongly affected by changing the periods over which the bias was defined. However this does not prove that the bias is stationary; instead it proves that the relative GCM performance is not affected by any bias non-stationarity. Christensen et al. (2008) used a set of RCMs covering Europe to examine the biases in precipitation and temperature extrapolated to different temperature regimes and found that bias non-stationarity was evident. These temporal and state dependent biases (Buser et al., 2009; Ehret et al., 2012) have been attributed to the poor representations in the dynamic and physical processes of models (Haerter et al., 2011). Furthermore, increases in global temperatures in the future may amplify some GCM biases through feedback processes (Hall et al., 2008). Buser et al. (2009) suggest that bias non-stationarity needs to be considered because the assumption of constant bias over time may lead to overconfidence in the precision of future projections. They proposed the idea of time varying additive or multiplicative bias corrections.

One of the factors that confounds attempts to examine bias non-stationarity is that as well as dynamic model errors, apparent bias can be evident due to sampling uncertainty if short time series are only used for either the models or observations. Therefore, it is important that the impacts of internal variability on the bias estimates are properly considered (Maraun, 2012). Another significant consideration is that most bias correction methods are applied to unconditional climatological 
distributions which do not account for the combination of different underlying biases depending on weather types, for example the type 1 errors as defined by Eden et al. (2012). An exception is the work of Bárdossy and Pegram (2011) who showed that considering biases in precipitation conditioned on circulation-patterns improves the representation of seasonal average rainfall. Li et al. (2016) extended this idea to allow the relative occurrence of each weather type to change in the future and assessed the effects on design rainfall estimates.

Previous work considering bias non-stationary assumptions have focussed on daily or monthly biases defined using reasonably short time series from GCMs (Maurer et al., 2013) and RCMs (Buser et al., 2009; Christensen et al., 2008; Maraun, 2012). Non-stationarity has also been considered in the context of statistical downscaling relationships using GCMs (Hewitson and Crane, 2006). However there has been limited work considering the non-stationarity of model biases at decadal and multi-decadal time scales which requires the use of century-long GCM simulations. Bias non-stationarity has also not been previously considered for the Australian continent. This paper addresses both these gaps. The extent of the problem is highlighted in Figure 1 where the time series from a single GCM and observations of surface air temperature for four different locations in Australia are provided. In Figure 1(a) the model and the observations both have similar trends and the difference between the model and observations stays reasonably constant over time. However this is clearly not the case in the other three locations where if the model bias was defined using the early part of the record, the bias estimate would be very different than if the later part of the record was used. It is also clear that the nature of the bias non-stationarity varies between these three locations with increasing bias evident in Figure 1(b) and decreasing bias in Figure 1(c). In Figure 1(d) the bias even changes direction over the historical period. For the locations in Figure 1, a simple annual mean bias correction has been applied using the first fifty years to calculate the bias and then applying this correction to the second half of the simulations. When the bias is constant over time (e.g Figure 1a) the bias correction is successful in improving the GCM simulations over the full time period. However it is clear that in Figure 1c that the assumption of bias stationarity actually degrades 
the GCM simulations after bias correction due to the nature of the bias non stationarity at this location.

\section{Figure 1:}

The purpose of this paper is to investigate the extent and nature of bias non-stationarity across Australia. This will be done by considering monthly precipitation and temperature simulations for the entire $20^{\text {th }}$ century. From the literature review it is clear that GCM biases may be non-stationary at daily and monthly time scales, however the influence of low-frequency variability on GCM bias properties over Australia requires investigation. Are there temporal and spatial patterns to systematic biases? The answers to these questions will also be discussed in the context of improving existing bias correction methods to address the types of issues shown in Figure 1.

\section{$2 \quad$ Data and methods}

\subsection{Data}

The Coupled Model Inter-comparison Project (CMIP5) experiments have been used to examine the nature of bias and the existence of bias non-stationarity in GCMs in Australia. Six GCMs with different spatial resolutions (Table 1) were analysed.

Table 1: CMIP5 GCMs used in the study

In this study we have selected two variables; air temperature and precipitation, since these are commonly used for impact assessments and have long and reasonably reliable gridded observation datasets. Monthly observed precipitation and temperature data have been used in this study because the available time series are longer and has less uncertainty than daily gridded data. The choice of observation data is important because any non-stationary biases may be the result of changes in the GCM, changes in the observations or changes in both. There is still some uncertainty in observational data sets and there is no clear guidance as to which dataset is preferable (Wehner et al., 2014). In some cases the variation between observational datasets is similar in magnitude to the 
model error, particularly when considering extremes (Gervais et al., 2014). To this end, we have examined the GCM biases using a number of different observation datasets and consider the sensitivity of the results to the choice of dataset.

Observed precipitation and air temperature data has been used from the Australian Water Availability Project (AWAP) which has a spatial resolution of $0.05^{\circ}$. The AWAP gridded dataset is produced using an optimised Barnes successive correction technique that creates a weighted average of the station data (Jones et al., 2009). For air temperature, the University of Delaware dataset was also used which has a spatial resolution of $0.5^{\circ}$ (Willmott and Robeson, 1995). For precipitation, the Global Precipitation Climatology Centre (GPCC) data base $\left(1^{\circ}\right)$ and Climatic Research Unit, University of East Anglia $\left(0.5^{\circ}\right)(\mathrm{CRU}, 2015)$ dataset have also been used. GPCC provides in situbased gridded monthly precipitation data sets at a spatial resolution of $1.0^{\circ}$ (Schneider et al., 2008). The monthly gridded CRU dataset is constructed using an "anomaly" approach, which attempts to maximize the available station data in space and time. Grids of monthly anomalies relative to a standard normal period were first derived. The anomaly grids were then combined with a highresolution $\left(0.5^{\circ}\right)$ mean monthly climatology to create the estimated monthly surface precipitation (New et al., 2000). To simplify the presentation, the results are reported for the AWAP precipitation and University of Delaware temperature datasets, with other dataset results presented in the supplementary information and summarised in Section 4.

The observed data for precipitation and temperature were re-gridded to the resolution of each GCM using area-averaging. The bias has been calculated at each grid cell individually and summarised using regional and continental level aggregations. Regional results are considered to account for the different large scale drivers that affect different parts of the country. Six regions were used for the analysis based on aggregating the regions defined by Perkins et al. (2007) and the regions are shown in Figure 2. Results from all the cells in a region were pooled to examine the bias properties over time. 


\section{Figure 2}

\subsection{Methods}

To assess the nature of the climate model bias, the GCM runs were compared to observations. Biases are calculated by considering a particular statistic e.g. mean, from the observations and the GCM simulations over a fixed time window. The percentage bias for precipitation is defined as the difference between the two estimates of the statistic (model minus observed) and scaled by the observed statistic to reflect the multiplicative bias correction that is usually applied to precipitation (Dosio and Paruolo, 2011; Hempel et al., 2013; Teutschbein and Seibert, 2012a). Additive biases in temperature are defined using the model estimate minus the observed. The first two moments have been used (mean and standard deviation) to represent how well the overall climatology is represented and how variability is characterised. Biases in the $10^{\text {th }}$ and $90^{\text {th }}$ quantiles were also calculated to understand how well more extreme values are captured by the climate models. Analyses were carried out at GCM's native grid resolution to avoid influencing the bias calculations by the choice of regridding method. Bias in the annual statistics was considered as well as on seasonal time scales, using four seasons. In northern Australia, another alternative would have been to consider a wet/dry season delineation but for consistency in the calculations standard 3-month seasons were used.

One of the important methodological choices is the length of the time window over which to calculate the model and observed statistics and the bias. The advantage of using GCM simulations and monthly data is that around 100 years of observed and modelled data is available. This gives considerable scope to investigate the influence of different window lengths on the stationarity of the bias estimates. Three different window lengths were investigated - 10 years, 25 years and 33 years. These correspond to dividing the 100 years of data into ten, four or three non-overlapping periods respectively. For each period, an estimate of the statistic of interest is obtained from the observations and a GCM and the biases calculated accordingly. Using ten-year periods to calculate bias introduces more uncertainty. These periods are shorter than those generally used to calculate climate statistics, 
although they are similar to the analysis lengths used by Maurer et al. (2013) when considering daily statistics. The advantage of the ten-year windows is that there are ten bias estimates which can provide information on the evolution of bias over time.

With climate change already evident (BOM\&CSIRO, 2014), increasing trends in temperature are expected. Ideally the GCMs should reflect this trend in their simulations as well. However to avoid discrepancies in the magnitude of the trends introducing spurious bias non-stationarity, both the observations and the GCM simulations of temperature were detrended prior to the bias analyses. A simple linear trend model was assumed to apply and least-squares-fit was used to detrend the data series.

Bootstrapping has been used to assess the uncertainty in the bias estimates and hence the significance of any non-stationarity that is found. One hundred bootstrap samples were created from the observations and the GCM simulations with no replacement. The bootstrapping was applied separately for each month to preserve the seasonal cycle within each year, although auto-correlation was neglected. Bias estimates for each statistic and time window were calculated from each bootstrap sample and used to calculate $95 \%$ confidence limits on the bias estimates. The bootstrapping provides estimates of the possible variability in bias if there was no bias non-stationarity. The actual bias can then be compared to the bootstrap samples to assess the significance of the actual bias. If there is no bias non-stationarity, then actual bias should lie within the bootstrapped estimates. If actual bias is outside the confidence limits from the bootstrap this is evidence that something other than chance is occurring (Hesterberg et al., 2005). The number of times the confidence limits are exceeded has been counted for each grid cell, time period and statistic and used to assess overall bias non-stationarity. 


\section{Results}

\subsection{Do biases vary with time?}

Using the GCMs simulation of the 20th century and re-gridded observations, the biases in the GCM simulations are calculated over different time scales and at the seasonal and annual level. If the assumption of bias stationarity is reasonable, then the bias should not change significantly from one period to another period. In Figure 3 the bias in the estimate of the annual mean (Figure 3a) and annual standard deviation (Figure 3b) are shown (red lines) for a single location using 10 year windows to calculate the statistics. The biases in the annual mean range from the GCM underestimating the mean by $50 \%$, to a slight overestimate of approximately $5 \%$. The biases in the estimates of the standard deviation of the yearly rainfall totals are even larger and more variable over time. These results illustrate that the assumption of bias stationarity may be flawed. Similar results are found for other window lengths and at other locations.

\section{Figure 3:}

Are the bias variations shown in Figure 3 statistically significant? As described in Section 2.2 both the observations and GCM data have been resampled. The hundred realisations of bias from the resampled time series and the corresponding $95 \%$ confidence limits on the bias estimates are also shown in Figure 3. It is clear from the resampling that the bias estimates are much more stable for the mean than the standard deviation. In most cases, the bias estimates from the GCM are consistent with the range of biases expected given 10-year length analysis windows. There are 3 periods where the bias is larger than expected and the same time periods show significantly different biases in both statistics, giving more weight to the conclusion that these variations are not just a result of sampling variability. According to the binomial distribution (Livezey and Chen, 1983) if we run only 10 independent tests, by chance, we would only expect to see one in five bias estimates fall outside the uncertainty bounds. This means, if two or more bias estimates out of the 10 lie outside the $95 \%$ confidence limit, non-stationarity is statistically significant. Figure 3 is clearly an example of 
significant non-stationarity. Table 2 shows the percentage of grid cells where significant temporal non-stationarity has been observed. All GCMs were found to have have non-stationarity in both bias statistics at least some locations..

Table 2: Extent of significant non-stationarity in 10-yr window for individual grid cells.

At this stage of the analysis is not clear if the biases are introduced by the temporal variations in the observations not being reflected in the GCM simulations or if the GCM simulations have varied whilst the observations have remained relatively constant.

In Table 3 and Table 4, the number of exceedances of the 95\% confidence intervals for each segment of time windows of 10 and 25 years has been counted and is reported as a percentage of the total number of grid cells for each GCM. The last column of each table summarises the average percentage of grids cells and across all time windows where the bias lies outside the confidence limits over all windows. Results for the 33-year window analysis are broadly similar to the 25 -year window case and are not presented here but are available on request.

Table 3: Percentage of locations where precipitation biases lie outside the $95 \%$ confidence intervals (10-year time window)

Table 4: Percentage of locations where precipitation biases lie outside the $95 \%$ confidence intervals (25-year time window)

It is clear from the tables that the number of exceedances of the confidence limits is not evenly distributed with time. There are time steps where exceedance is more common than in others, particularly around the mid-century. It is also clear that the patterns of non-stationarity are very model dependent which indicates that the biases are likely due to the GCMs themselves as if it was a problem with the observations then we would expect to see more consistency in the bias nonstationarity across models. 
Field significance tests of the results in Tables 3 and 4 were carried out (Livezey and Chen, 1983) and the significant results considering the whole analysis domain are highlighted in bold. The thresholds for significant results across the whole analysis domain vary because the model resolution and hence number of grid cells is different for each model. The field significance tests are based on assuming that the biases at individual grid cells are spatially independent. This assumption is considered reasonable because bias corrections are applied independently at each grid cell. To test this assumption the degrees of freedom of the spatial bias fields have been assessed using the chisquared method (Wang and Shen, 1999). The degrees of freedom and resulting implications for the field significance of the non-stationarity are provided in the supplementary material. In general the conclusions with respect to non-stationarity are the same as the results presented in Table 3 and Table 4. The largest changes in significant non-stationarity are seen for CSIROMk3.6 for the 10 year windows and for MIROC5 for the 25 year windows.

Considering the average percentage of exceedances for each model, in most cases this is higher than the respective significance level of the model. The exceptions are CanESM2 and CESM1-CAM5 and IPSLCM5A-LR where the bias in the mean only occurs at around 5\% of grid cells on average. Bias non-stationarity is more of an issue for the standard deviation estimates than the mean. This is to be expected as climate models are generally considered more reliable in representing climatology than higher order statistics like standard deviation. Interestingly the percentage of locations where bias estimates lie outside the confidence limits is higher for the 25year window compared to the 10-year window. This may reflect the stability in the resampled bias estimates over the longer period so that the bias non-stationarity is easier to identify. Generally 25year windows are considered representative of climatology so dividing the analysis period into four approximates these climatological estimates and highlights that the identified bias non-stationarity is not just due to noisy estimates because of short record lengths.

How do the temperature bias properties compare to these results for precipitation? It is generally considered that climate models have more skill in surface temperature simulations than 
precipitation (Gleckler et al., 2008; Xu and Yang, 2012). However the results in Figure 4 show that there is still considerable even more non-stationarity in the temperature biases and possibly even more than seen in the precipitation biases. This may be a result of less natural variability in observed temperatures than precipitation leading to narrower confidence limits and more ability to detect significant bias changes. Although, the non-stationarity counts vary in magnitude for different GCMs, there are some consistent patterns particularly in the extensive non-stationary evident around the middle of the $20^{\text {th }}$ century and almost all the non-stationarity is evident in the second half of the period. Given that the temperature data was detrended prior to the bias analysis this is not attributed to increasing trends in temperature from anthropogenic climate change. Consistent bias nonstationarity in precipitation occurs a little later, around the 1970 s.

\section{Figure 4:}

Aggregating the simulations to the annual scale results may mask potential non-stationarity at seasonal or other short time scales. This may be caused by different physical process or feedbacks operating within the climate system and/or the models at different times of the year. At a particular location, there may be significant non-stationary bias behaviour in one season, which might not be apparent in other season/seasons. Figure 5(a) and 5(b) shows biases at a single location but for different seasons.

\section{Figure 5}

Biases in mean summer precipitation lie outside the confidence limits three times out of ten but in autumn they are fairly stationary. On the other hand, the standard deviation shows almost the opposite pattern. Table 5 summarises the number of exceedances for seasonal mean bias, which is calculated by taking the average number exceedances from all time steps for the 10 and 25 -year windows respectively. As before, field significance is indicated with bold text. As expected the annual results mask some seasonal patterns. For example, in CSIRO-Mk3.6 average exceedance in the 10 -year window show that precipitation non-stationary biases in the mean are more likely in 
summer and spring (September-February) compared to the other half of the year. For BNU-ESM the annual bias non-stationary is much more of a problem than the seasonal bias non-stationarity which implies that biases in one season and time period tend to also occur in subsequent seasons for the same time period, leading to larger bias non-stationarity at the annual scale.

Table 5: Average $\%$ of grid where precipitation biases in seasonal mean exceed $95 \%$ confidence intervals

As evident from the results presented so far, there are at least some locations and times of year where bias non-stationarity is considerable. How consistent are these results when considered regionally or over the whole continent? Do some GCMs show more bias non-stationarity than other GCMs? To answer these questions, further analysis was done to interpret the spatial patterns of the bias. Spatial patterns of non-stationary biases are quite clear in Figure 6, where the number of exceedances of the $95 \%$ confidence limits at each grid cell is shown for temperature and precipitation for two of the GCMs.

\section{Figure 6:}

Non-stationarity in the temperature biases covers more areas than precipitation for both models agreeing with the time varying results presented previously. The model differences are also evident in Figure 6 where there are many more locations in MIROC5 showing bias non-stationarity than in CESM1-CAM5. Results for other GCMs show a similar range of variations. Being a large continent, the Australian climate has significant variation in temperature/precipitation in different regions. Figure 6 shows is a general tendency of bias non-stationarity occurring more in the southeast part of the continent than in other parts of the continent, especially for temperature. This might be the result of the presence of Great Dividing Range that dominates the eastern Australia landmass and has influence on the regional climate. 


\subsection{Can bias non-stationarity be explained?}

It is clear from the discussion in the previous section that there is strong evidence of bias nonstationarity in some GCMs. There was clear evidence of more bias non-stationarity in the middle part of the century for temperature and in the latter part of the historical record for precipitation. The evidence of more non-stationarity in 25-year windows compared to 10-year windows suggests that low-frequency variability in the observations may be represented differently in GCMs. Lowfrequency variability and its drivers are further investigated in this section.

Low-frequency variability in Australian climate system is due to large-scale multi-year and multi-decadal climate teleconnections like El Niño Southern Oscillation (ENSO) (Cane, 1992), the Indian Ocean Dipole (IOD) (Saji et al., 1999; Ummenhofer et al., 2008) and the Interdecadal Pacific Oscillation (IPO) (Power et al., 1999a). Given the patterns of bias non-stationarity at 25-year times scales observed in the previous section, one possible reason may be the representation of IPO within the models. This section investigates this point in more detail.

IPO is a leading mode of sea surface temperature (SST) variations seen mostly in the Pacific Ocean (Dai, 2013; Kiem et al., 2003; Power et al., 1999b). The IPO is sometimes regarded as the Pacific-wide manifestation of the Pacific Decadal Oscillation (PDO) (Folland et al., 2002; Mantua et al., 1997; Pui et al., 2011) although recently Westra et al. (2015) suggested that it may be just a different manifestation of ENSO as a result of smoothing. IPO has found to be associated with fluctuations in rainfall (Latif et al., 1997; Power et al., 1998), runoff (Verdon et al., 2004) and temperature (Power et al., 1999b) over Australia on inter-decadal time scales. The negative (positive) phase of the IPO has been associated with increased (decreased) rainfall primarily in east Australia (Latif et al., 1997; Power et al., 1999a). On the other hand, temperatures over Australia are warmer during positive IPO phases compared to the negative phase (Arblaster et al., 2002). It has been documented that climate models do not adequately represent the magnitude and occurrence of interannual climate cycles (AchutaRao and Sperber, 2006; Bellenger et al., 2014; Mehrotra and 
Sharma, 2010) that influence Australian climate. For example, the correlation in climate models between the IPO index and Australian rainfall was found to be only -0.3 compared to an observed value of -0.8 (Arblaster et al., 2002). IPO may be a low-frequency representation of ENSO indices (Power et al., 2006; Westra et al., 2015) and CMIP5 models have been found to represent ENSO poorly; one-third of the models have an ENSO amplitude that differs more than $25 \%$ of the observed value (Bellenger et al., 2014). These statistics indicate that IPO may not be very well represented in CMIP5 and this poor representation of large-scale atmospheric cycles like IPO could be one reason for the GCM biases that are observed (Rocheta et al., 2014b).

The IPO phases are broadly defined in the same way in a number of studies (Folland et al., 2002; Kiem and Franks, 2004; Power et al., 1999a; Pui et al., 2011; Salinger, 2005; Verdon et al., 2004) with slight differences in the start and end times. For the purposes of this study the definition of Kiem and Franks (2004) was adopted, which defines the positive phases as 1900-1910, 1924-1943 and 1979-1997 and the negative phases as 1914-1922, 1946-1957 and 1968-1976. Sensitivity analyses were performed by modifying the IPO definition to match that used by Folland et al. (2002) and Salinger (2005); it was found that the results were broadly the same.

Biases in the rainfall and temperature were calculated for positive and negative IPO phases. The procedure is the same as the fixed window analysis in the previous section, just that only two estimates result; one for the composite negative phases and one for the positive phases. Considering first the biases in the mean temperature between the two phases, Figure 7 shows the bias estimates for each grid cell and each GCM. For all the GCMs, the majority of the points lie slightly above the one-to-one line. This means that positive temperature biases tend to be larger in the IPO negative phase, but that the biases are improved slightly in the IPO negative phase if the model tends to underestimate temperatures in general. Positive biases suggest that the GCM is too warm and that this effect is amplified during IPO negative phases when observed temperatures are generally lower. For CSIRO-MK3.6 the biases are mostly negative, which means that this particular GCM is 
underestimating temperature; on the other hand, MIROC5 tends to overestimate annual mean temperature, therefore biases are mostly positive and are larger in the IPO negative phase.

\section{Figure 7}

Considering the bias in mean yearly precipitation, non-stationarity between the two IPO phases is also observed (Figure 8). However, in this case, the IPO positive phase bias tends to be higher than IPO negative phase bias. The difference between the two bias estimates tends to be larger when the absolute values of the biases are also large. The precipitation bias is mostly positive, which indicates that the GCMs overestimate the observed rainfall. The IPO negative phase is associated with generally wetter conditions so if the GCM overestimates rainfall this effect will be mitigated during the negative phase as seen in Figure 8 by the slightly lower biases during the negative phase.

\section{Figure 8:}

How do the biases behave for other statistics? The results for the annual standard deviation of precipitation are shown in Figure 9. Biases in the standard deviation are again mainly positive, indicating that the GCMs often overestimate variability at the yearly time scale. However, the biases are generally smaller in the IPO negative phase. In this phase given overall higher rainfall, the standard deviations of the observed time series are likely to be higher and, therefore, the GCM better captures this feature. In the drier IPO positive phase if rainfall is lower the GCM overestimates of both mean and standard deviation of rainfall lead to larger biases. Interestingly there is less spatial correlation between the biases in the two phases for the standard deviation than seen in the mean; see for example IPSL-CM5A-LR where bias in one phase is not correlated to bias in the other phase. This suggests that the bias non-stationarity is not just a result of under-represented interdecadal variability but that there are completely different interdecadal cycles in the GCM from the observations. There is less non-stationarity in the temperature standard deviation biases indicating either than that the GCMs have better skill in portraying this feature than the precipitation or that there is less variation in standard deviations of temperature between the two phases. Similar 
differences in the bias for the two IPO phases are found for the $10^{\text {th }}$ and $90^{\text {th }}$ percentiles of the monthly temperature and precipitation.

\section{Figure 9}

Given that the IPO has varying impacts on different parts of Australia, the results in the previous section have been stratified according to the regions shown previously in Figure 2. Boxplots showing the range of biases in each region for the two phases are provided in Figure 10 for temperature and Figure 11 for precipitation. The significance of the differences at a regional level has been assessed using a paired Wilcoxon Rank-Sum test. Where a significant difference was found, the boxplots have been hatched.

\section{Figure 10}

\section{Figure 11}

For all GCMs the significant differences between the two phases are found in Region 1, 2, 3 and 6. The bias differences between the phases are never significant in Region 4 and 5. Regions 4 and 5 are located in South Australia and Western Australia, where IPO impacts are known to be smaller than the east coast and tropics. There are some interesting patterns in the precipitation biases (Figure 11) in different regions from the different GCMs. For example, IPSL biases are reasonably constant across the continent whilst the MIROC5 biases are substantially higher in the central and western parts of Australia than the east coast. We note that even though the biases are significantly different between the IPO phases, this non-stationarity is generally smaller (on average $5-30 \%$ ) than the magnitude of the overall bias between the GCM and the observations (up to 150\%). This suggests that the bias non-stationarity is a second order effect when considering model errors. However it is the consistency of the bias non-stationarity with respect to the IPO phases that is an important finding from this study. If the GCMs had no skill in representing IPO the differences between the IPO positive and negative phases would be same for all models and would be the same as the 
difference in the observations for these two phases. If the GCMs could completely accurately represent the IPO phases then there would be no bias non-stationarity evident. Thus the results here suggest the GCMs have some ability to represent such multi decadal climate teleconnections but that there are remaining biases.

\section{Discussion and implications for bias correction}

Bias correction studies often ignore the fact that alternate observational datasets for the same time period and spatial domain, may differ significantly from each other. This is especially true for fine small time steps and, in places where few point observations exist. This issue was investigated in the context of the present study, the aim being to confirm that the bias non-stationarity documented in earlier sections, was not an artefact of a specific observational dataset being used. To answer this question, all bias statistics were re-assessed using the different observed data sets as described in Section 2. For temperature, the AWAP dataset was used to re-estimate the bias statistics. For precipitation, GPCC and CRU datasets were used in the observation sensitivity analyses. Figure 12 shows the results of these sensitivity tests for precipitation bias stationarity using GPCC and CRU.

\section{Figure 12}

In this figure, three GCMs have been selected to compare the results from the two observation datasets and the results can also be compared to the AWAP results shown in Figure 11. For both datasets, similar bias non-stationarity is evident in all GCMs for regions 1, 2, 3, 5 and 6, where significant differences in biases between the IPO phases are found similar to the AWAP analyses. In region 4, there are some small differences in the significance of the bias non-stationarity when calculated using the different observations. Similar results are found for the temperature bias (Supplementary Information S1). It is the clear that the overall conclusions are the not changed by the choice of observation source. 
It is clear from the results presented here that bias non-stationarity is indeed an issue over parts of Australia when considering fixed time windows and also known drivers of interdecadal variability. This builds on previous research which has mainly focussed on daily time scale data and short window lengths for the bias calculations. By carrying out the calculations using monthly data and considering decadal and multi-decadal windows this study has highlighted the extent of the problem and regionally varying nature of the biases. GCMs are able to represent our current climate with some skill but reasonably large biases are clear in variables such as precipitation which will affect the accuracy and conclusions of climate impact assessments for example hydrologic simulations (Hansen et al., 2006; Sharma et al., 2007). Improving climate models is an ongoing task and therefore bias correction will remain an important step in impact studies for the foreseeable future.

Would one expect similar non-stationarity to be evident in finer scale simulations (using higher resolution GCMs or post-processed/downscaled using regional climate models)? We argue that the non-stationarity demonstrated here manifests itself across all scales and in the lateral boundary conditions supplied by GCMs in a dynamical downscaling process. This has been shown to the case in dynamical downscaling applications (Rocheta et al., 2014a) with recommendations being to bias correct these lateral boundary conditions before the actual downscaling. As this bias correction again does not explicitly account for non-stationarity, the outcome is expected to be consistent with the results shown here.

What should be done to improve bias correction approaches given the results found in this study? The simplest modification to existing bias correction approaches is to allow the bias correction terms to vary linearly with time, similar to the approach suggested by Buser et al. (2009). However, it is clear from the fixed window analyses presented here that it is difficult to describe bias non-stationarity with a linear trend and hence we believe that for Australian conditions this may not be an appropriate solution. The patterns in the multi-decadal variability of the biases seen here suggest that one approach for bias correction techniques would be to condition the bias on the state 
of the climate teleconnections. However, this would require these climate teleconnections to be reliability identified both in the current climate simulations and in the future projections. Given the uncertainties in defining these climate teleconnections even in the observations and the errors in the representation of ENSO in climate models, it is considered unlikely that a climate teleconnection conditioning bias correction approach will be easy to develop. It may be more practical to use assessments of bias non-stationary in climate models to select subsets of the available GCMs where the bias stationarity assumption is valid and use this reduced model set in subsequent impact assessments.

\section{Conclusion}

In this study, simulations from six CMIP5 GCMs for the last century have been used to test whether the assumption of bias stationarity commonly used in bias correction approaches is reasonable. Bias patterns were identified through two different approaches: using (1) fixed time windows and (2) stratifying according to IPO phases. Both approaches demonstrated significant nonstationary behaviour in the GCM's biases.

No consistent trends in bias were found using the fixed window approach suggesting that modifying bias correction methods to include a simple trend in bias will not be sufficient to address these problems. When considering multidecadal variability significant differences in bias periods between wet and dry epochs were found. Regional analyses further confirmed these findings with the strongest differences seen on the east coast of Australia where IPO impacts tend to be the strongest. Interestingly this effect was seen in all GCMs the used in this study. It is therefore concluded that using the same method of bias correction for different IPO phases may not effectively increase the accuracy of GCM simulations and the assumption of bias stationarity should be treated very carefully in bias correction studies.

\section{Acknowledgement}


The comments from two anonymous reviewers greatly improved the presentation of this work. The authors gratefully acknowledge the World Climate Research Programme's Working Group on Coupled Modelling, which is responsible for CMIP, and thank the climate modelling groups (Listed in Table 1 of this paper) for producing and making available their model output that served as the basis of the results reported here. For CMIP, the U.S Department of Energy's Program for Climate Model Diagnosis and Intercomparison provides coordinating support and led development of software infrastructure in partnership with the Global Organization for Earth System Science Portals. Air temperature data used in this research was provided by the NOAA/OAR/ESRL PSD, Boulder, Colorado, USA, from their Web site at http://www.esrl.noaa.gov/psd/. The authors also acknowledge the Australian Research Council for partial funding for this work.

\section{$6 \quad$ References}

AchutaRao, K., Sperber, K.R., 2006. ENSO simulation in coupled ocean-atmosphere models: are the current models better? Climate Dynamics, 27(1): 1-15.

Allen, M.R., Kettleborough, J., Stainforth, D., 2002. Model error in weather and climate forecasting, ECMWF Predictability of Weather and Climate Seminar. European Centre for Medium Range Weather Forecasts, Reading, UK, http://www. ecmwf. int/publications/library/do/references/list/209.

Arblaster, J., Meehl, G., Moore, A., 2002. Interdecadal modulation of Australian rainfall. Climate Dynamics, 18(6): 519-531. DOI:10.1007/s00382-001-0191-y

Bárdossy, A., Pegram, G., 2011. Downscaling precipitation using regional climate models and circulation patterns toward hydrology. Water Resources Research, 47(4).

Bellenger, H., Guilyardi, E., Leloup, J., Lengaigne, M., Vialard, J., 2014. ENSO representation in climate models: from CMIP3 to CMIP5. Climate Dynamics, 42(7-8): 1999-2018.

Boberg, F., Christensen, J.H., 2012. Overestimation of Mediterranean summer temperature projections due to model deficiencies. Nature Climate Change, 2(6): 433-436.

BOM\&CSIRO, 2014. State of the climate 2014 Bureau of Meteorology, CSIRO.

Buser, C.M., Künsch, H.R., Lüthi, D., Wild, M., Schär, C., 2009. Bayesian multi-model projection of climate: Bias assumptions and interannual variability. Climate Dynamics, 33(6): 849-868.

Cane, M., 1992. Tropical Pacific ENSO models: ENSO as a mode of the coupled system. Cambridge University Press Cambridge, pp. 583-614.

Christensen, J.H., Boberg, F., Christensen, O.B., Lucas-Picher, P., 2008. On the need for bias correction of regional climate change projections of temperature and precipitation. Geophysical Research Letters, 35(20). DOI:10.1029/2008GL035694

Christensen, O., Gaertner, M., Prego, J., Polcher, J., 2001. Internal variability of regional climate models. Climate Dynamics, 17(11): 875-887.

CRU, 2015. High-resolution gridded datasets (and derived products). In: Climatic Research Unit, U.o.E.A. (Ed.). DOI:http://www.cru.uea.ac.uk/cru/data/hrg/cru_ts_3.23/cruts.1506241137.v3.23/

Dai, A., 2013. The influence of the inter-decadal Pacific oscillation on US precipitation during 1923-2010. Climate dynamics, 41(3-4): 633-646.

Dosio, A., Paruolo, P., 2011. Bias correction of the ENSEMBLES high-resolution climate change projections for use by impact models: Evaluation on the present climate. Journal of Geophysical Research: Atmospheres (1984-2012), 116(D16). 
Eden, J.M., Widmann, M., Grawe, D., Rast, S., 2012. Skill, correction, and downscaling of GCM-simulated precipitation. Journal of Climate, 25(11): 3970-3984.

Ehret, U., Zehe, E., Wulfmeyer, V., Warrach-Sagi, K., Liebert, J., 2012. HESS Opinions" Should we apply bias correction to global and regional climate model data?". Hydrology and Earth System Sciences Discussions, 9(4): 5355-5387.

Folland, C.K., Renwick, J.A., Salinger, M.J., Mullan, A.B., 2002. Relative influences of the Interdecadal Pacific Oscillation and ENSO on the South Pacific Convergence Zone. Geophysical Research Letters, 29(13): 21-1-21-4. DOI:10.1029/2001GL014201

Gervais, M., Gyakum, J.R., Atallah, E., Tremblay, L.B., Neale, R.B., 2014. How well are the distribution and extreme values of daily precipitation over North America represented in the Community Climate System Model? A comparison to reanalysis, satellite, and gridded station data. Journal of Climate, 27(14): 5219-5239.

Giorgi, F., Coppola, E., 2010. Does the model regional bias affect the projected regional climate change? An analysis of global model projections. Climatic Change, 100(3-4): 787-795.

Gleckler, P.J., Taylor, K.E., Doutriaux, C., 2008. Performance metrics for climate models. Journal of Geophysical Research D: Atmospheres, 113(6).

Gobiet, A., Suklitsch, M., Heinrich, G., 2015. The effect of empirical-statistical correction of intensitydependent model errors on the temperature climate change signal. Hydrology and Earth System Sciences, 19(10): 4055-4066.

Haerter, J., Hagemann, S., Moseley, C., Piani, C., 2011. Climate model bias correction and the role of timescales. Hydrology and Earth System Sciences, 15(3): 1065-1079.

Hagemann, S., Chen, C., Haerter, J.O., Heinke, J., Gerten, D., Piani, C., 2011. Impact of a statistical bias correction on the projected hydrological changes obtained from three GCMs and two hydrology models. Journal of Hydrometeorology, 12(4): 556-578.

Hall, A., Qu, X., Neelin, J., 2008. Improving predictions of summer climate change in the United States. Geophysical Research Letters, 35(1): L01702.

Hansen, J.W., Challinor, A., Ines, A., Wheeler, T., Moron, V., 2006. Translating climate forecasts into agricultural terms: advances and challenges. Climate research, 33(1): 27-41.

Hawkins, E., Sutton, R., 2011. The potential to narrow uncertainty in projections of regional precipitation change. Climate Dynamics, 37(1-2): 407-418.

Hempel, S., Frieler, K., Warszawski, L., Schewe, J., Piontek, F., 2013. A trend-preserving bias correction-the ISI-MIP approach. Earth System Dynamics, 4(2): 219-236.

Hesterberg, T., Moore, D.S., Monaghan, S., Clipson, A., Epstein, R., 2005. Bootstrap methods and permutation tests. Introduction to the Practice of Statistics, 5: 1-70.

Hewitson, B., Crane, R., 2006. Consensus between GCM climate change projections with empirical downscaling: precipitation downscaling over South Africa. International Journal of Climatology, 26(10): 1315-1337.

Ho, C.K., Stephenson, D.B., Collins, M., Ferro, C.A., Brown, S.J., 2012. Calibration strategies: a source of additional uncertainty in climate change projections. Bulletin of the American Meteorological Society, 93(1): 21-26.

IPCC, 2014. Summary for Policymakers. In: Climate Change 2014: Impacts, Adaptation, and Vulnerability. Part A: Global and Sectoral Aspects. Contribution of Working Group II to the Fifth Assessment Report of the Intergovernmental Panel on Climate Change

Johnson, F., Sharma, A., 2009. Measurement of GCM Skill in Predicting Variables Relevant for Hydroclimatological Assessments. Journal of Climate, 22(16): 4373-4382. DOI:10.1175/2009JCLI2681.1

Johnson, F., Sharma, A., 2012. A nesting model for bias correction of variability at multiple time scales in general circulation model precipitation simulations. Water Resources Research, 48(1). DOI:10.1029/2011WR010464

Johnson, F., Sharma, A., 2015. What are the impacts of bias correction on future drought projections? Journal of Hydrology, 525: 472-485.

Jones, D.A., Wang, W., Fawcett, R., 2009. High-quality spatial climate data-sets for Australia. Australian Meteorological and Oceanographic Journal, 58(4): 233. 
Kerkhoff, C., Künsch, H.R., Schär, C., 2014. Assessment of Bias Assumptions for Climate Models. Journal of Climate(2014).

Kiem, A.S., Franks, S.W., 2004. Multi-decadal variability of drought risk, eastern Australia. Hydrological Processes, 18(11): 2039-2050.

Kiem, A.S., Franks, S.W., Kuczera, G., 2003. Multi-decadal variability of flood risk. Geophysical Research Letters, 30(2).

Latif, M., Kleeman, R., Eckert, C., 1997. Greenhouse warming, decadal variability, or El Nino? An attempt to understand the anomalous 1990s. Journal of Climate, 10(9): 2221-2239.

Li, H., Sheffield, J., Wood, E.F., 2010. Bias correction of monthly precipitation and temperature fields from Intergovernmental Panel on Climate Change AR4 models using equidistant quantile matching. Journal of Geophysical Research: Atmospheres (1984-2012), 115(D10).

Li, J., Sharma, A., Evans, J., Johnson, F., 2016. Addressing the mischaracterization of extreme rainfall in regional climate model simulations-A synoptic pattern based bias correction approach. Journal of Hydrology.

Livezey, R.E., Chen, W., 1983. Statistical field significance and its determination by Monte Carlo techniques. Monthly Weather Review, 111(1): 46-59.

Macadam, I., Pitman, A., Whetton, P., Abramowitz, G., 2010. Ranking climate models by performance using actual values and anomalies: Implications for climate change impact assessments. Geophysical Research Letters, 37(16): L16704.

Mantua, N.J., Hare, S.R., Zhang, Y., Wallace, J.M., Francis, R.C., 1997. A Pacific Interdecadal Climate Oscillation with Impacts on Salmon Production. Bulletin of the American Meteorological Society, 78(6): 1069-1079. DOI:10.1175/1520-0477(1997)078<1069:APICOW>2.0.CO;2

Maraun, D., 2012. Nonstationarities of regional climate model biases in European seasonal mean temperature and precipitation sums. Geophysical Research Letters, 39(6).

Masson, D., Knutti, R., 2011. Spatial-scale dependence of climate model performance in the CMIP3 ensemble. Journal of Climate, 24(11): 2680-92. DOI:10.1175/2011JCLI3513.1

Maurer, E., Das, T., Cayan, D., 2013. Errors in climate model daily precipitation and temperature output: time invariance and implications for bias correction. Hydrology and Earth System Sciences, 17(6): 21472159.

Mehrotra, R., Sharma, A., 2010. Development and application of a multisite rainfall stochastic downscaling framework for climate change impact assessment. Water Resources Research, 46(7).

Mehrotra, R., Sharma, A., 2015. Correcting for systematic biases in multiple raw GCM variables across a range of timescales. Journal of Hydrology, 520(HYDROL17331): 214-223. DOI:10.1016/j.jhydrol.2014.11.037

New, M., Hulme, M., Jones, P., 2000. Representing twentieth-century space-time climate variability. Part II: Development of 1901-96 monthly grids of terrestrial surface climate. Journal of climate, 13(13): 2217-2238.

Perkins, S., Pitman, A., Holbrook, N., McAneney, J., 2007. Evaluation of the AR4 climate models' simulated daily maximum temperature, minimum temperature, and precipitation over Australia using probability density functions. Journal of climate, 20(17): 4356-4376.

Piani, C., Haerter, J.O., Coppola, E., 2010. Statistical bias correction for daily precipitation in regional climate models over Europe. Theoretical and Applied Climatology, 99(1-2): 187-192.

Power, S., Casey, T., Folland, C., Colman, A., Mehta, V., 1999a. Inter-decadal modulation of the impact of ENSO on Australia. Climate Dynamics, 15(5): 319-324.

Power, S., Haylock, M., Colman, R., Wang, X., 2006. The predictability of interdecadal changes in ENSO activity and ENSO teleconnections. Journal of Climate, 19(19): 4755-4771.

Power, S., Tseitkin, F., Mehta, V., Lavery, B., Torok, S., Holbrook, N., 1999b. Decadal climate variability in Australia during the twentieth century. International Journal of Climatology, 19(2): 169-184.

Power, S., Tseitkin, F., Torok, S., Lavery, B., Dahni, R., McAvaney, B., 1998. Australian temperature, Australian rainfall and the Southern Oscillation, 1910-1992: coherent variability and recent changes. Australian Meteorological Magazine, 47(2): 85-101.

Pui, A., Lal, A., Sharma, A., 2011. How does the Interdecadal Pacific Oscillation affect design floods in Australia? Water Resources Research, 47(5). 
Randall, D.A., Wood, R.A., Bony, S., Colman, R., Fichefet, T., Fyfe, J., Kattsov, V., Pitman, A., Shukla, J., Srinivasan, J., 2007. Climate models and their evaluation. Climate change, 323.

Richardson, K., Steffen, W., Schellnhuber, H.J., Alcamo, J., Barker, T., Kammen, D.M., Leemans, R., Liverman, D., Munasinghe, M., Osman-Elasha, B., 2009. Climate change-global risks, challenges \& decisions: synthesis report. Museum Tusculanum.

Rocheta, E., Evans, J., Sharma, A., 2014a. Assessing atmospheric bias correction for dynamical consistency using potential vorticity. Environ Res Lett, 9(12). DOI:10.1088/1748-9326/9/12/124010

Rocheta, E., Sugiyanto, M., Johnson, F., Evans, J., Sharma, A., 2014b. How well do general circulation models represent low-frequency rainfall variability? Water Resources Research, 50(3): 2108-2123.

Saji, N., Goswami, B.N., Vinayachandran, P., Yamagata, T., 1999. A dipole mode in the tropical Indian Ocean. Nature, 401(6751): 360-363.

Salinger, M.J., 2005. Climate Variability and Change: Past, Present and Future - An Overview. Climatic Change, 70(1-2): 9-29. DOI:10.1007/s10584-005-5936-x

Schneider, U., Fuchs, T., Meyer-Christoffer, A., Rudolf, B., 2008. Global precipitation analysis products of the GPCC. Global Precipitation Climatology Centre (GPCC), DWD, Internet Publikation, 112.

Sharma, D., Das Gupta, A., Babel, M., 2007. Spatial disaggregation of bias-corrected GCM precipitation for improved hydrologic simulation: Ping River Basin, Thailand. Hydrology and Earth System Sciences, 11(4): 1373-1390.

Sun, Y., Solomon, S., Dai, A., Portmann, R.W., 2006. How often does it rain? Journal of Climate, 19(6): 916934.

Teutschbein, C., Seibert, J., 2012a. Bias correction of regional climate model simulations for hydrological climate-change impact studies: Review and evaluation of different methods. Journal of Hydrology, 456: 12-29.

Teutschbein, C., Seibert, J., 2012b. Is bias correction of Regional Climate Model (RCM) simulations possible for non-stationary conditions? Hydrology and Earth System Sciences Discussions, 9(11): 1276512795.

Teutschbein, C., Seibert, J., 2013. Is bias correction of regional climate model (RCM) simulations possible for non-stationary conditions? Hydrology and Earth System Sciences, 17(12): 5061-5077.

Ummenhofer, C.C., Sen Gupta, A., Pook, M.J., England, M.H., 2008. Anomalous rainfall over southwest Western Australia forced by Indian Ocean sea surface temperatures. Journal of Climate, 21(19): 5113-5134.

Verdon, D.C., Wyatt, A.M., Kiem, A.S., Franks, S.W., 2004. Multidecadal variability of rainfall and streamflow: Eastern Australia. Water Resources Research, 40(10): W10201. DOI:10.1029/2004WR003234

Wang, X., Shen, S.S., 1999. Estimation of spatial degrees of freedom of a climate field. Journal of climate, 12(5): 1280-1291.

Wehner, M.F., Reed, K.A., Li, F., Bacmeister, J., Chen, C.T., Paciorek, C., Gleckler, P.J., Sperber, K.R., Collins, W.D., Gettelman, A., 2014. The effect of horizontal resolution on simulation quality in the Community Atmospheric Model, CAM5. 1. Journal of Advances in Modeling Earth Systems, 6(4): 980997.

Westra, S., Renard, B., Thyer, M., 2015. The ENSO-precipitation teleconnection and its modulation by the Interdecadal Pacific Oscillation. Journal of Climate(2015).

Willmott, C.J., Robeson, S.M., 1995. Climatologically aided interpolation (CAI) of terrestrial air temperature. International Journal of Climatology, 15(2): 221-229.

Wood, A.W., Leung, L.R., Sridhar, V., Lettenmaier, D., 2004. Hydrologic implications of dynamical and statistical approaches to downscaling climate model outputs. Climatic change, 62(1-3): 189-216.

Xu, Z., Yang, Z.-L., 2012. An improved dynamical downscaling method with GCM bias corrections and its validation with 30 years of climate simulations. Journal of Climate, 25(18): 6271-6286. DOI:10.1175/JCLI-D-12-00005.1 


\section{Figure Captions}

Figure 1: Time series of GCM simulations and observations for temperature in the 20th century at 4 different locations, showing the variety of biases that are evident from a single GCM simulation.

Figure 2: Six Australia regions used to spatially aggregate bias statistics.

Figure 3: Bias changes over time for yearly precipitation in 10-year windows for (a) mean and (b) standard deviation. Thick red line is the model bias, dashed grey lines are the bias estimates based on the resampled data, and two black lines indicate $95 \%$ confidence intervals.

Figure 4: Exceedance of confidence interval for different GCMs in case of temperature and precipitation. Black lines indicate different GCMs. Y-axis shows the \% count of grid cells of a GCM for each 10 year window where bias in yearly mean exceeds $95 \%$ intervals. Red dots indicate the windows where bias non-stationarity is statistically significant.

Figure 5: Exceedance of confidence interval for mean and standard deviation of seasonal bias in precipitation for 10-year window. Bias behaviour at same location (south-west of region-4) in Summer (a, c) and Autumn (b, d) respectively. The thick red line is real data, thin grey lines are shuffled data, and two black lines indicate $95 \%$ confidence intervals.

Figure 6: Maps showing non-stationary behaviour of biases in yearly mean using 10 year time window for MIROC and CESMI-CAM5. Light circles indicate that biases in that grid never exceeds the $95 \%$ confidence intervals and dark circles show increasing numbers of exceedances.

Figure 7: IPO -ve vs IPO +ve biases in mean temperature in absolute unit. Black circles define grid cells for each GCM

Figure 8: IPO -ve vs IPO +ve bias in mean Precipitation. Black circles define grid cells for each GCM. 
Figure 9: IPO- vs IPO+ bias in SD of yearly precipitation. The difference in two biases is more significant at higher $\%$.

Figure 10: IPO- and IPO+ bias in mean temperature at different climate regions. White block indicates IPO+ and Gray indicates IPO-, hatch is used to indicate where there are significant differences in the biases in the IPO phases

Figure 11: IPO- and IPO+ bias in mean precipitation at different climate regions. White block indicates IPO+ and Gray indicates IPO-, hatch is used to indicate where there are significant differences in the biases in the IPO phases.

Figure 12: IPO- and IPO+ bias in mean precipitation at different climate regions using GPCC (left) and CRU (right) precipitation. 


\section{Table Captions}

Table 1: CMIP5 GCMs used in the study

Table 2: Extent of significant non-stationarity in 10-yr window at individual grid scale.

Table 3: Percentage of locations where precipitation biases lie outside the $95 \%$ confidence intervals (10-year time window)

Table 4: Percentage of locations where precipitation biases lie outside the $95 \%$ confidence intervals (25-year time window)

Table 5: Average $\%$ of grid where precipitation biases in seasonal mean exceed $95 \%$ confidence intervals. 


\section{Figures}

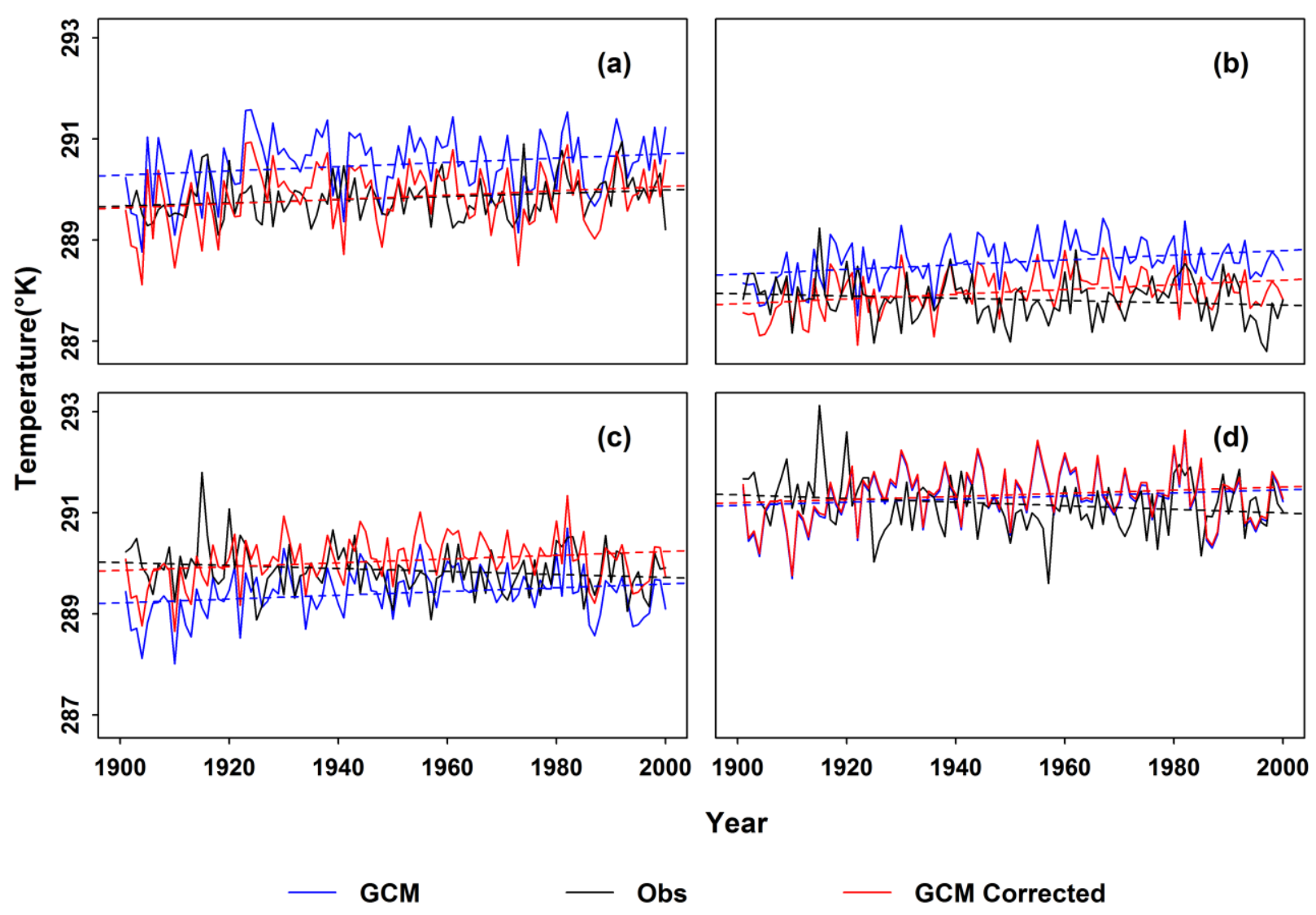

Figure 1: Time series of GCM simulations and observations for temperature in the 20th century at 4 different locations, showing the variety of biases that are evident from a single GCM simulation. 


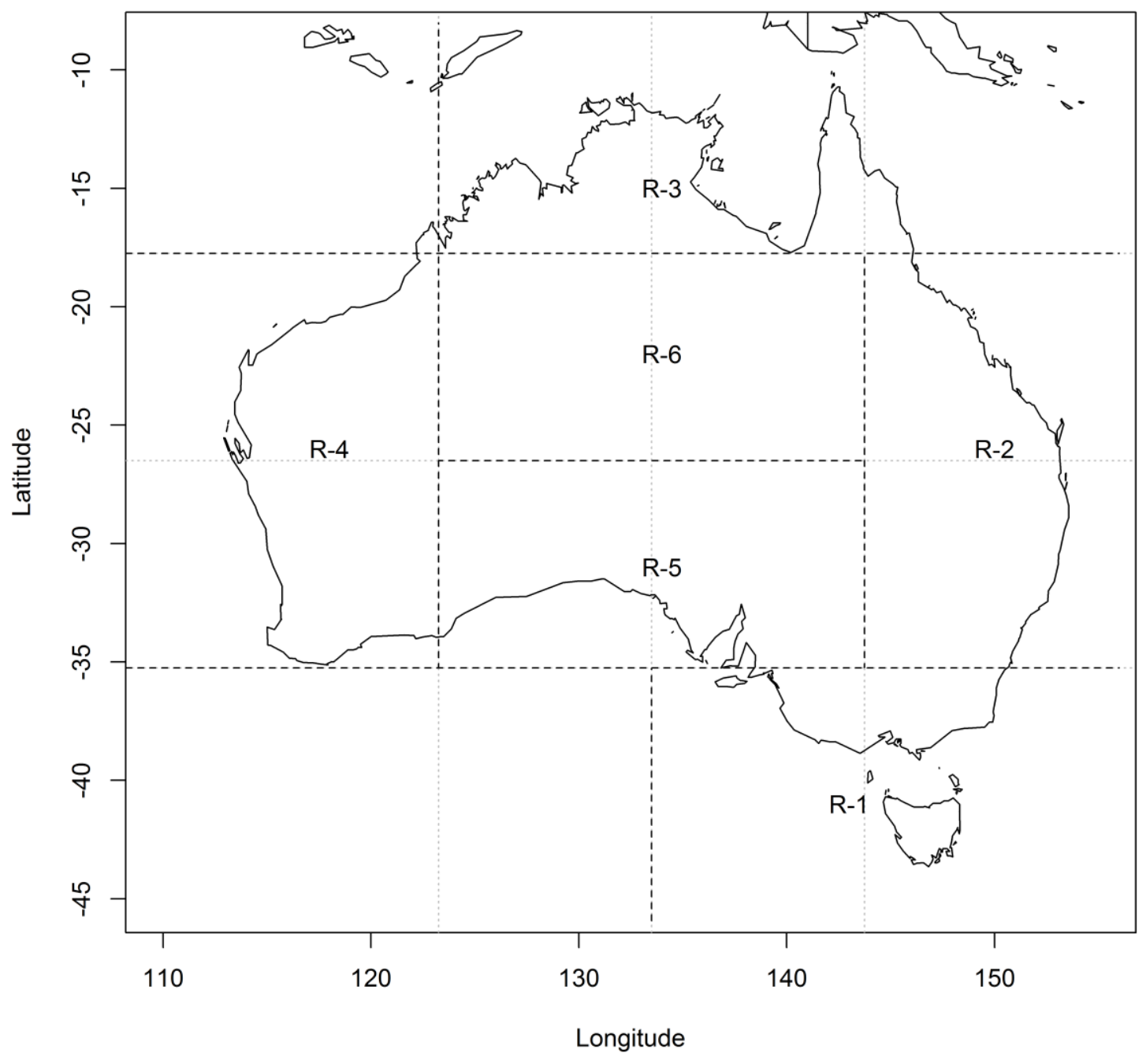

Figure 2: Six Australia regions used to spatially aggregate bias statistics. 

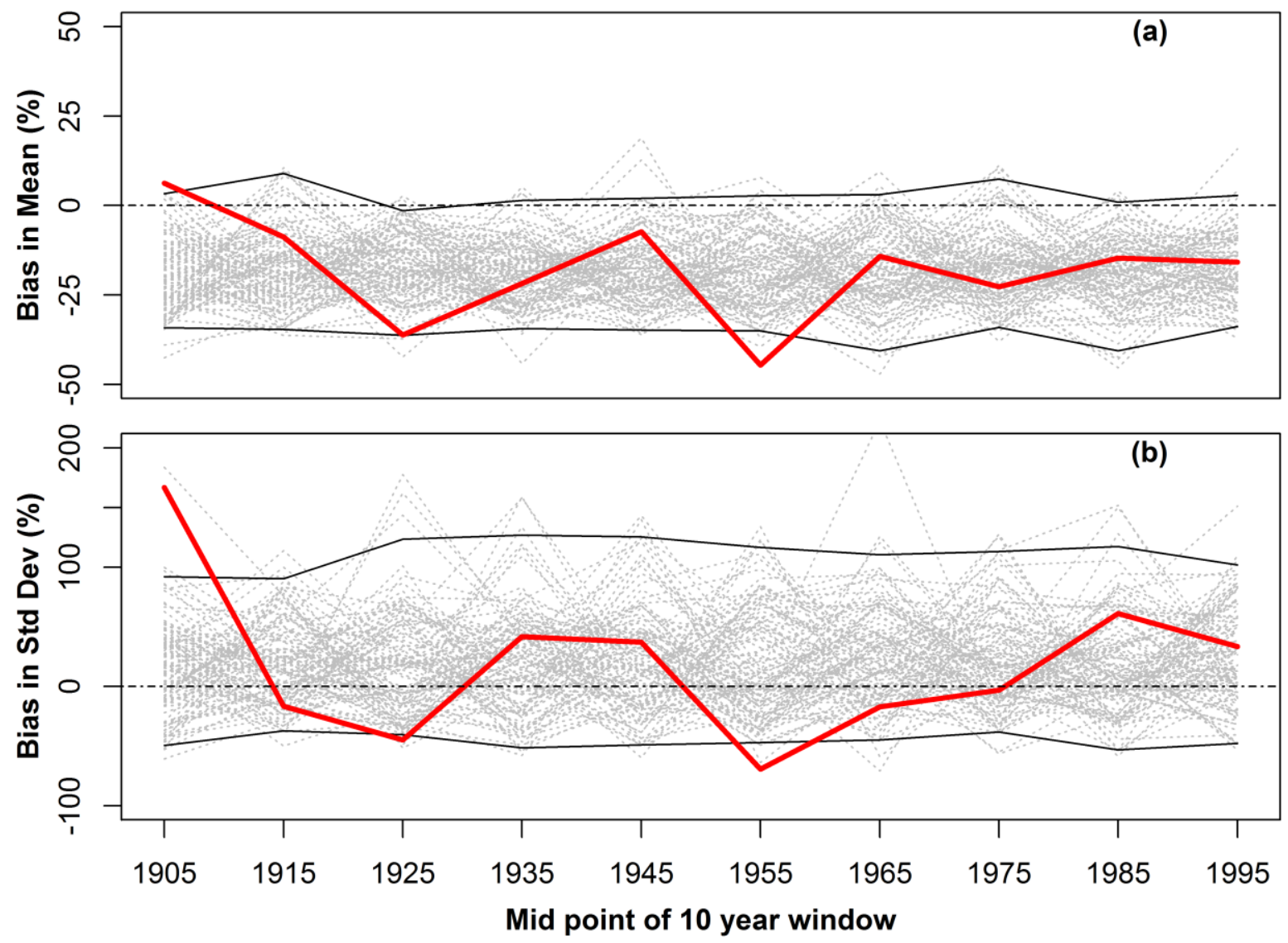

Figure 3: Bias changes over time for yearly precipitation in 10-year windows for (a) mean and (b) standard deviation. Thick red line is the model bias, dashed grey lines are the bias estimates based on the resampled data, and two black lines indicate $95 \%$ confidence intervals. 


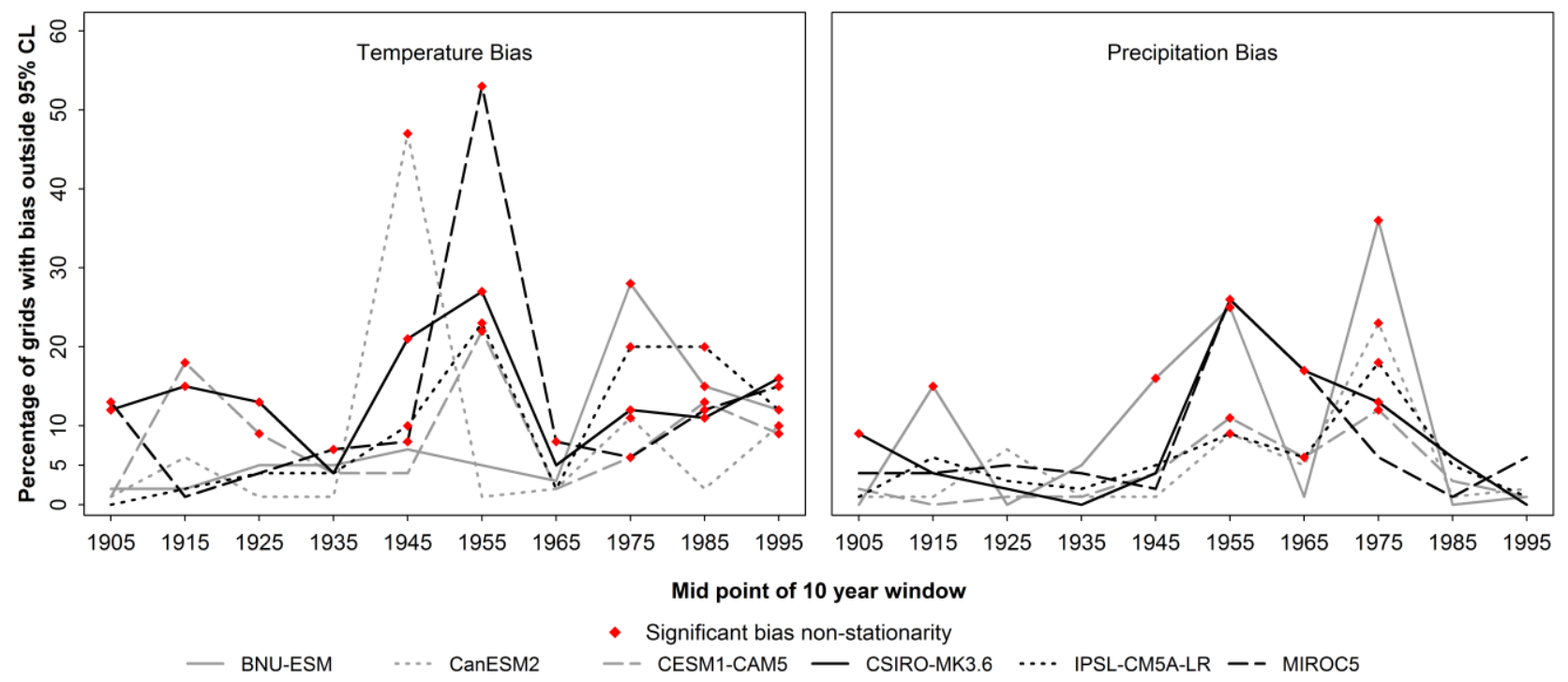

Figure 4: Exceedance of confidence interval for different GCMs in case of temperature and precipitation. Black lines indicate different GCMs. Y-axis shows the \% count of grid cells of a GCM for each 10 year window where bias in yearly mean exceeds $95 \%$ intervals. Red dots indicate the windows where bias non-stationarity is statistically significant. 

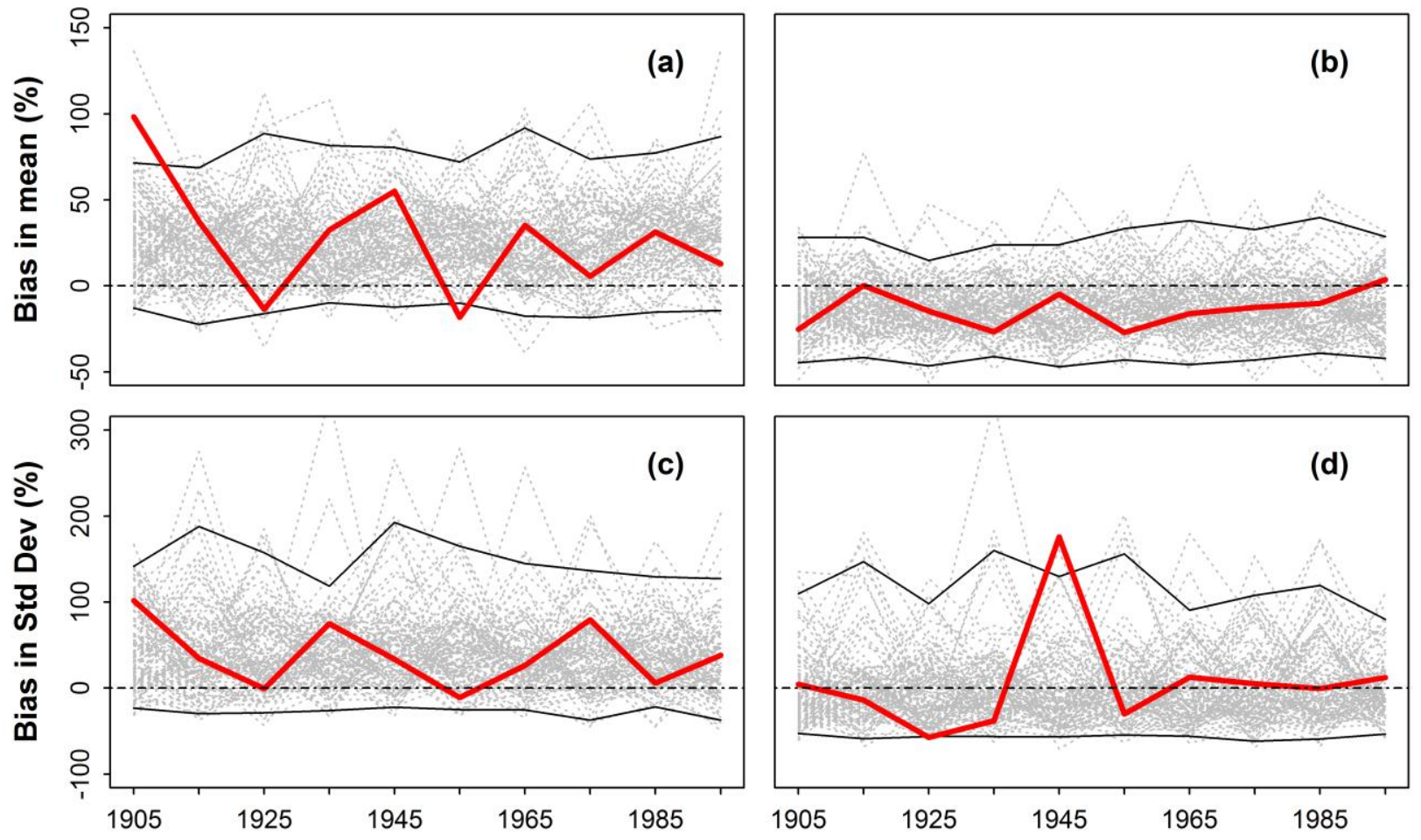

Mid point of 10 year window

Figure 5: Exceedance of confidence interval for mean and standard deviation of seasonal bias in precipitation for 10-year window. Bias behaviour at same location (south-west of region-4) in Summer (a, c) and Autumn (b, d) respectively. The thick red line is real data, thin grey lines are shuffled data, and two black lines indicate $95 \%$ confidence intervals. 

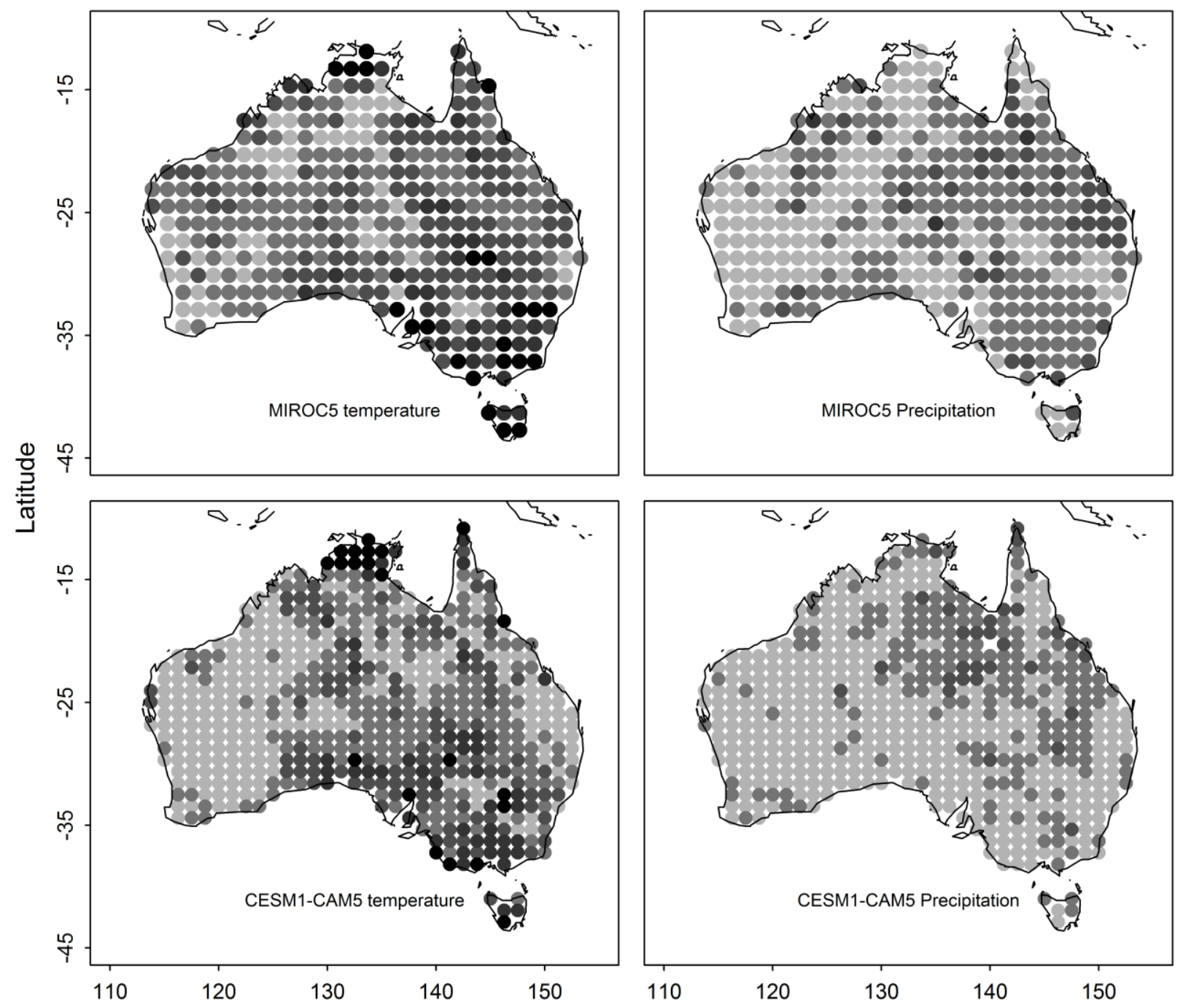

Longitude

- no exceedence $\bullet 2$ exceedence

- 1 exceedence $\bullet 3$ exceedence

Figure 6: Maps showing non-stationary behaviour of biases in yearly mean using 10 year time window for MIROC and CESMI-CAM5. Light circles indicate that biases in that grid never exceeds 
the $95 \%$ confidence intervals and dark circles show increasing numbers of exceedances.
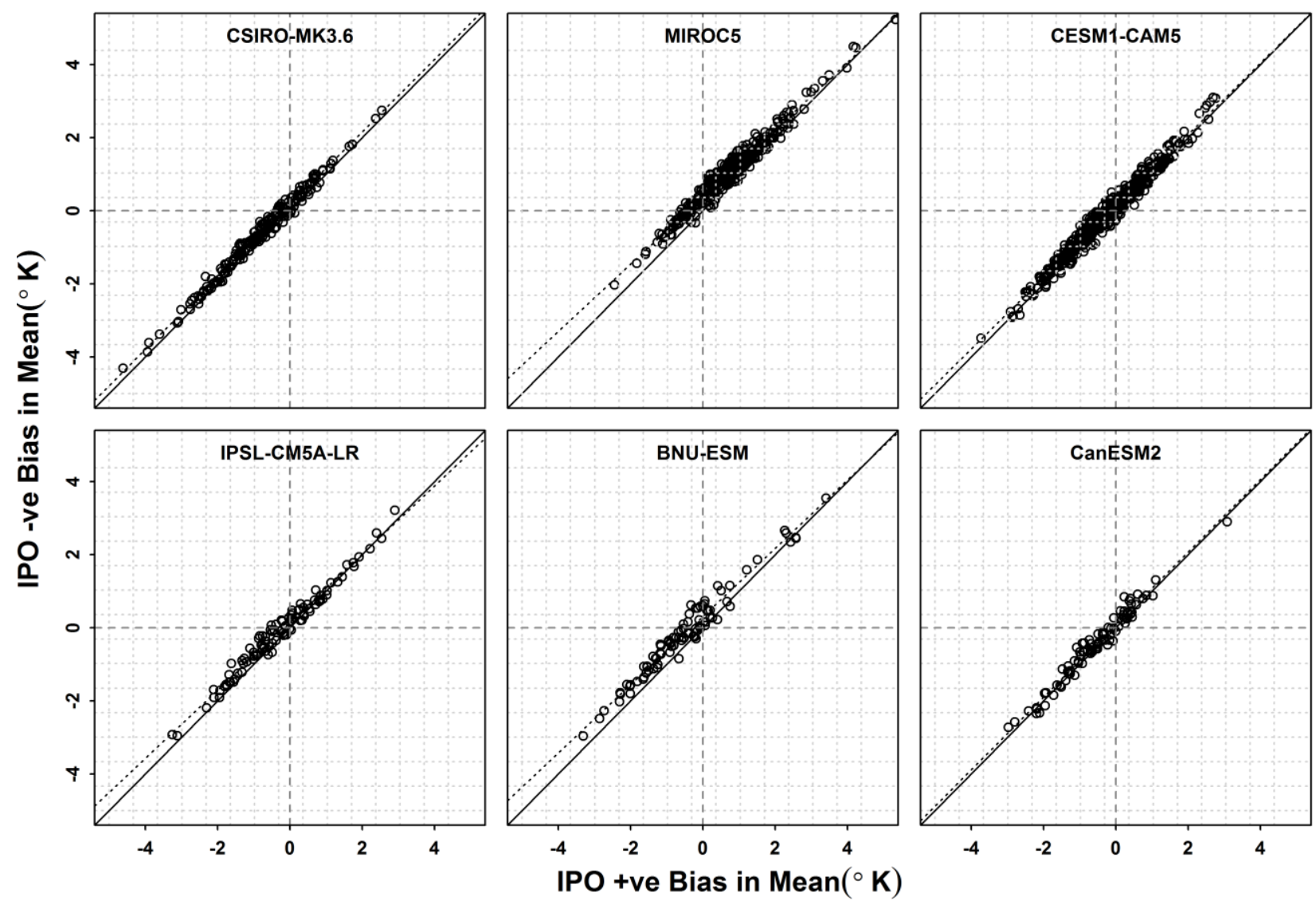

Figure 7: IPO -ve vs IPO +ve biases in mean temperature in absolute unit. Black circles define grid cells for each GCM 

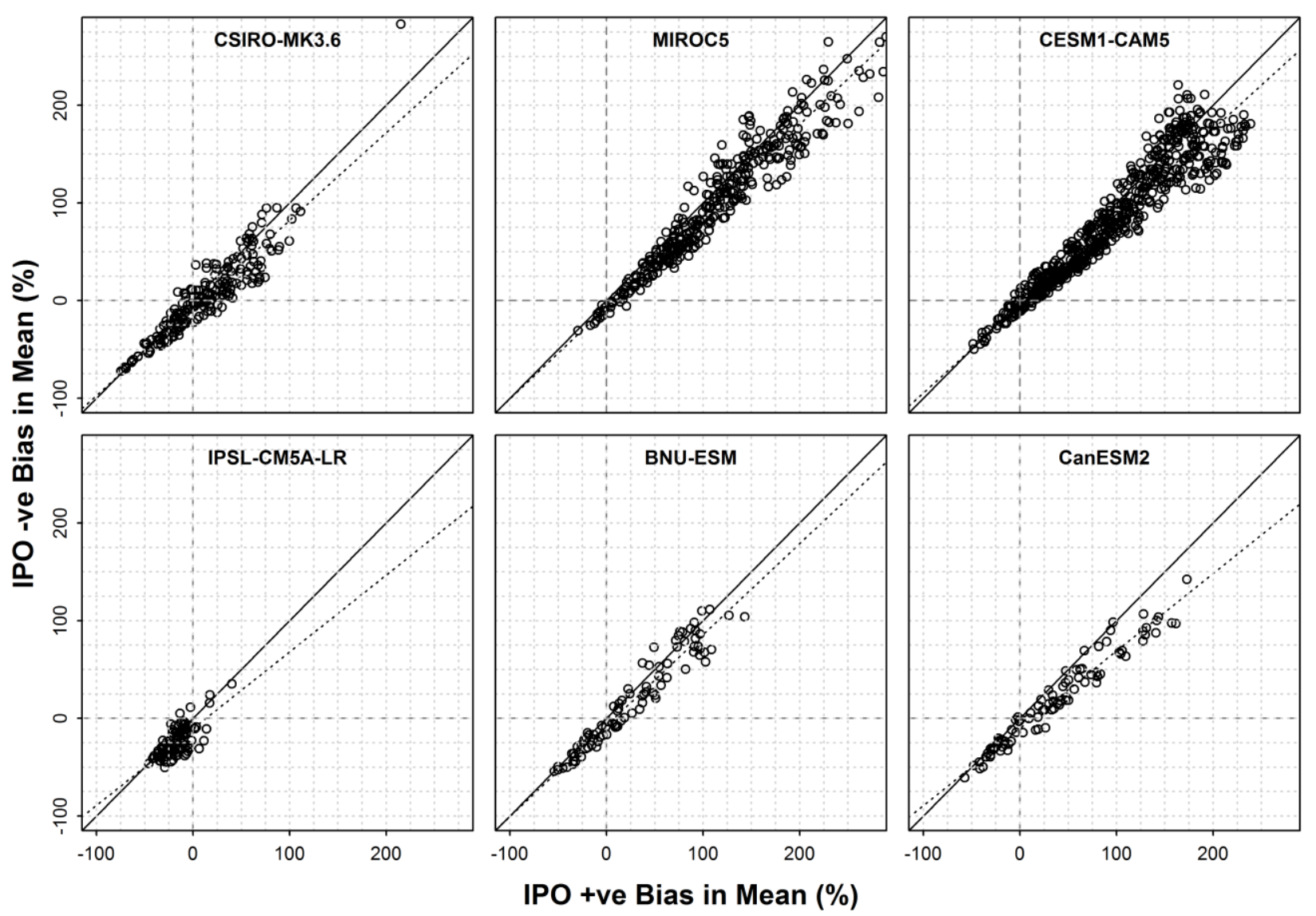

Figure 8: IPO -ve vs IPO +ve bias in mean Precipitation. Black circles define grid cells for each GCM. 

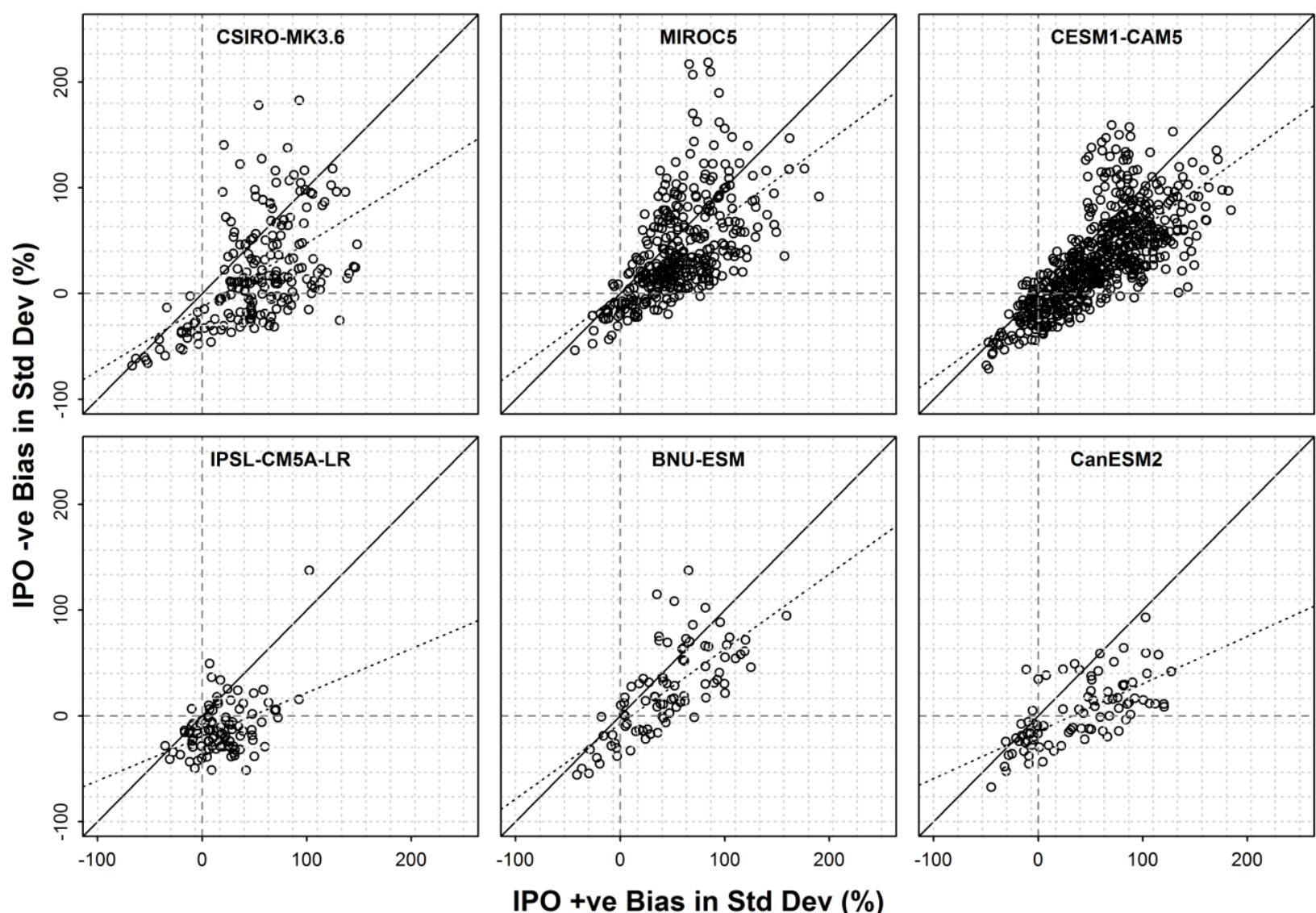

Figure 9: IPO- vs IPO+ bias in SD of yearly precipitation. The difference in two biases is more significant at higher $\%$. 

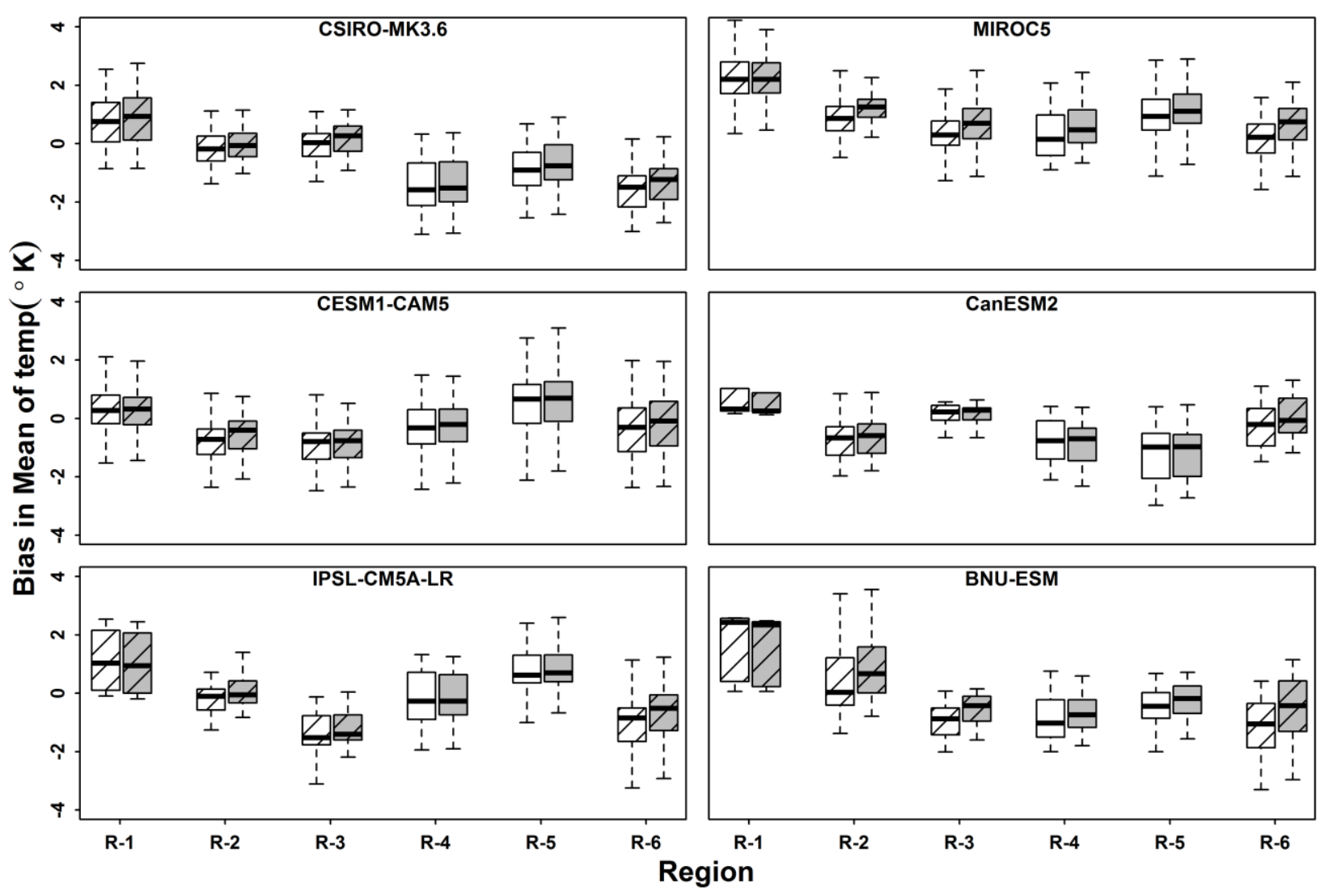

$\square$ IPO+ with significant p-value $\square$ IPO+ with non-significant p-value

IPO- with signifacent p-value $\square$ IPO- with non-signifacent p-value

Figure 10: IPO- and IPO+ bias in mean temperature at different climate regions. White block indicates IPO+ and Gray indicates IPO-, hatch is used to indicate where there are significant differences in the biases in the IPO phases 


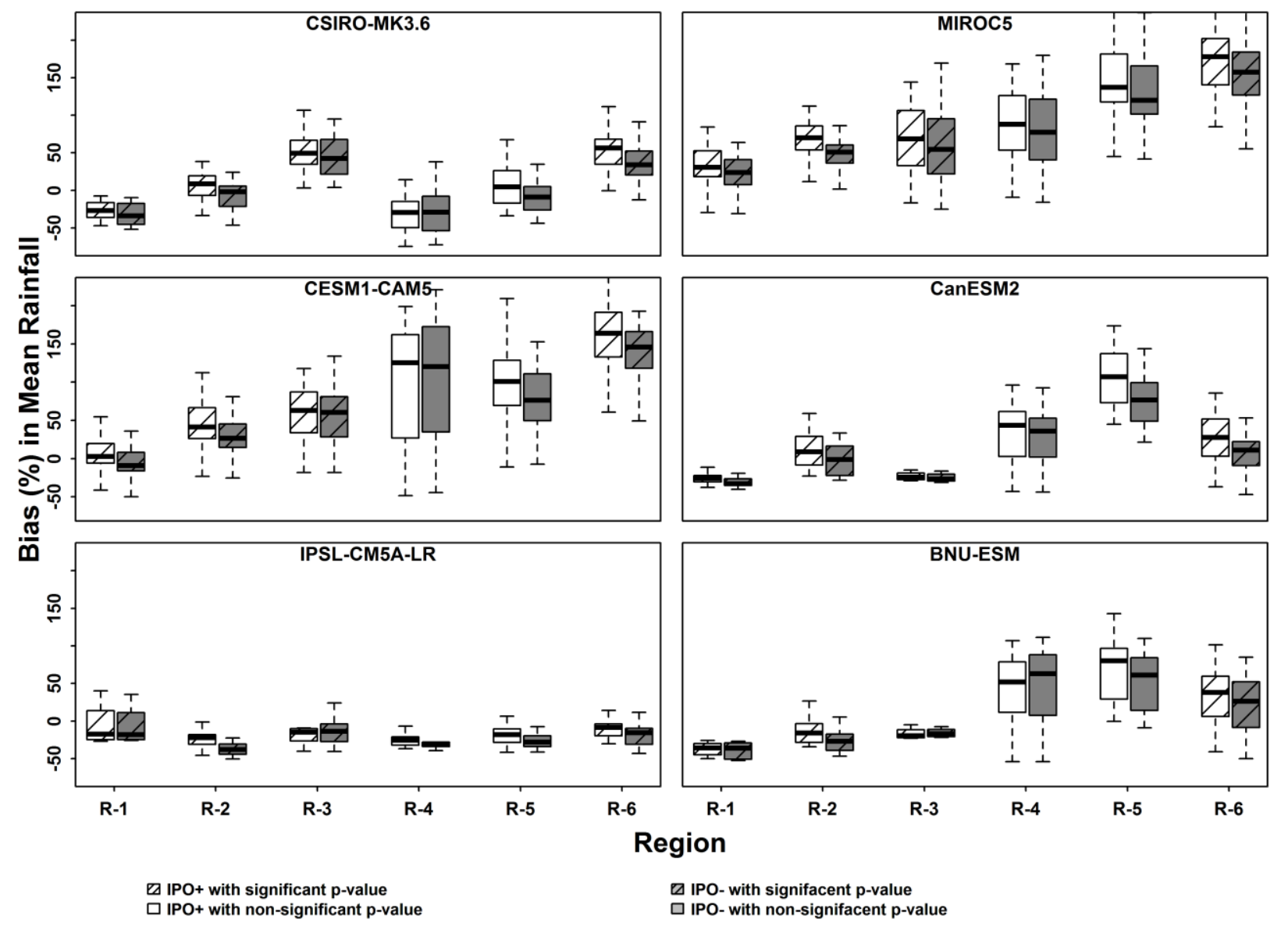

Figure 11: IPO- and IPO+ bias in mean precipitation at different climate regions. White block indicates IPO+ and Gray indicates IPO-, hatch is used to indicate where there are significant differences in the biases in the IPO phases. 


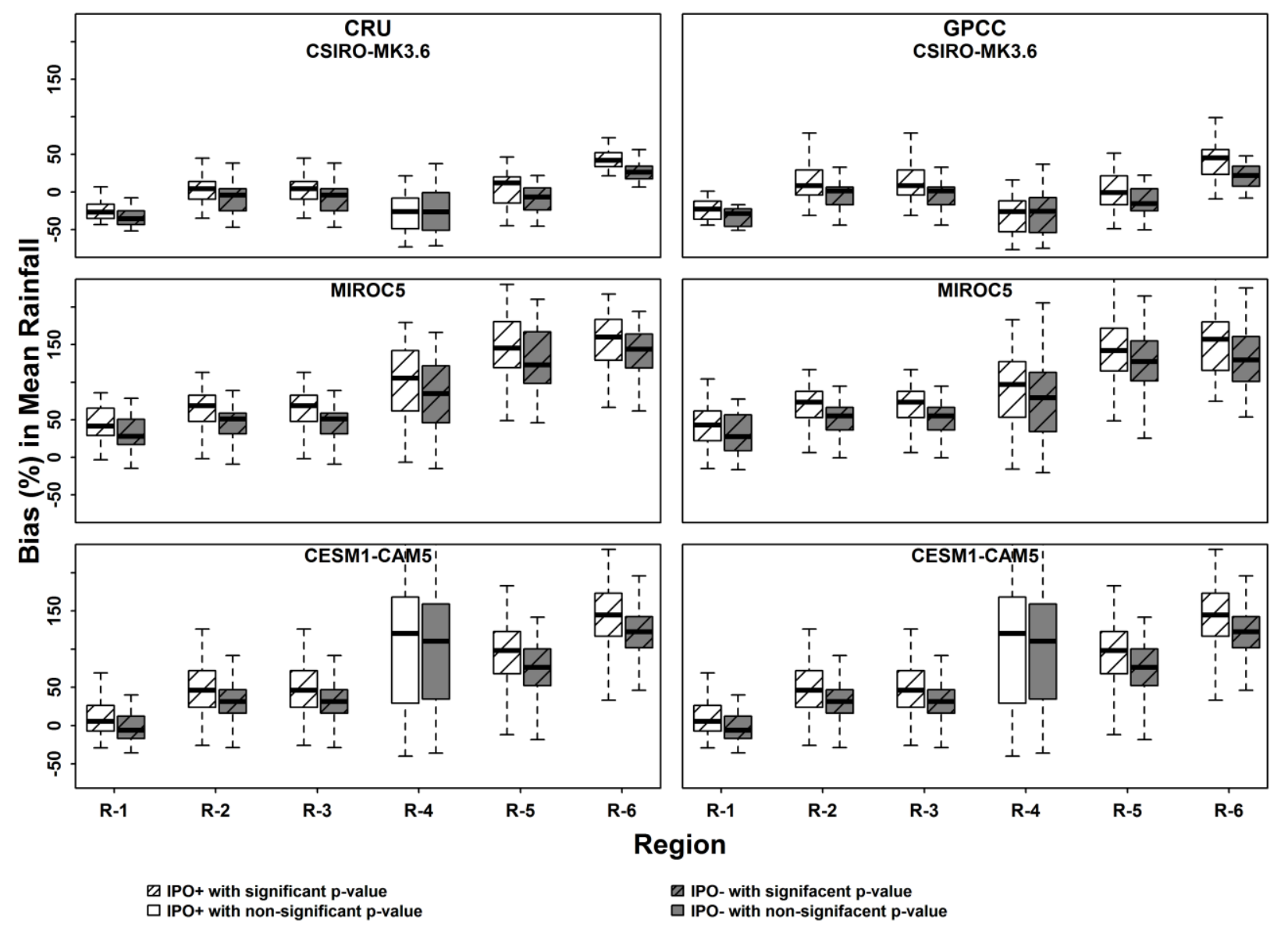

Figure 12: IPO- and IPO+ bias in mean precipitation at different climate regions using GPCC (left) and CRU (right) precipitation. 
Table 1. CMIP5 GCMs used in the study

\begin{tabular}{|c|c|c|c|}
\hline Modelling Center & Model Name & $\begin{array}{l}\text { Spatial } \\
\text { Resolution } \\
\text { (degrees) }\end{array}$ & $\begin{array}{c}\text { Number of } \\
\text { grids in } \\
\text { Australian land } \\
\text { mass }\end{array}$ \\
\hline $\begin{array}{l}\text { Commonwealth Scientific and Industrial Research } \\
\text { Organization in collaboration with Queensland } \\
\text { Climate Change Centre of Excellence (CSIRO- } \\
\text { QCCCE) }\end{array}$ & CSIRO-MK3-6-0 & $1.875 \times 1.85$ & 202 \\
\hline $\begin{array}{l}\text { Atmosphere and Ocean Research Institute (The } \\
\text { University of Tokyo), National Institute for } \\
\text { Environmental Studies, and Japan Agency for } \\
\text { Marine-Earth Science and Technology (MIROC) }\end{array}$ & MIROC5 & $1.406 \times 1.40$ & 350 \\
\hline $\begin{array}{l}\text { Community Earth System Model Contributors } \\
\text { (NSF-DOE-NCAR) }\end{array}$ & CESM1-CAM5 & $1.25 \times 0.94241$ & 588 \\
\hline Institut Pierre-Simon Laplace (IPSL) & IPSL-CM5A-LR & $3.75 \times 1.89474$ & 99 \\
\hline $\begin{array}{l}\text { College of Global Change and Earth System Science, } \\
\text { Beijing Normal University (GCESS ) }\end{array}$ & BNU-ESM & $2.8 \times 2.79$ & 88 \\
\hline $\begin{array}{l}\text { Canadian Centre for Climate Modelling and } \\
\text { Analysis(CCCma) }\end{array}$ & CanESM2 & $\begin{array}{c}2.8125 \mathrm{X} \\
2.79055\end{array}$ & 88 \\
\hline
\end{tabular}

Table 2: Extent of significant non-stationarity in 10-yr window at individual grid scale.

\begin{tabular}{|c|c|c|c|c|}
\hline \multirow{2}{*}{ GCM Name } & \multicolumn{4}{|c|}{$\begin{array}{c}\text { \% of grid cells where significant non- } \\
\text { stationarity exists }\end{array}$} \\
\cline { 2 - 5 } & \multicolumn{2}{|c|}{ Temperature } & \multicolumn{2}{c|}{ Rainfall } \\
\cline { 2 - 5 } & Mean & Std.dev & Mean & Std.dev \\
\hline BNU-ESM & 20 & 49 & 20 & 30 \\
\hline CanESM2 & 16 & 12 & 7 & 18 \\
\hline CESM1-CAM5 & 24 & 20 & 5 & 12 \\
\hline CSIRO-MK3.6 & 42 & 15 & 24 & 20 \\
\hline IPSL-CM5A-LR & 30 & 14 & 15 & 16 \\
\hline MIROC5 & 34 & 18 & 14 & 15 \\
\hline
\end{tabular}


Table 3. Percentage of locations where precipitation biases lie outside the $95 \%$ confidence intervals (10-year time window)

\begin{tabular}{|c|c|c|c|c|c|c|c|c|c|c|c|c|}
\hline $\begin{array}{l}\text { GCM Name } \\
\text { and number of } \\
\text { grid cells }\end{array}$ & & $\begin{array}{c}1900 \\
- \\
1909\end{array}$ & $\begin{array}{c}1910 \\
- \\
1919\end{array}$ & $\begin{array}{c}1920 \\
- \\
1929\end{array}$ & $\begin{array}{c}1930 \\
- \\
1939\end{array}$ & $\begin{array}{c}1940 \\
- \\
1949\end{array}$ & $\begin{array}{c}1950 \\
- \\
1959\end{array}$ & $\begin{array}{c}1960 \\
- \\
1969\end{array}$ & $\begin{array}{c}1970 \\
- \\
1979\end{array}$ & $\begin{array}{c}1980 \\
- \\
1989\end{array}$ & $\begin{array}{c}1990 \\
- \\
1999\end{array}$ & $\begin{array}{c}\text { Avg } \\
\%\end{array}$ \\
\hline \multirow[t]{2}{*}{ BNU-ESM } & Mean & 0 & 15 & 0 & 5 & 16 & 25 & 1 & 36 & 0 & 1 & 10 \\
\hline & SD & 6 & 10 & 3 & 12 & 34 & 6 & 2 & 35 & 8 & 2 & 12 \\
\hline \multirow[t]{2}{*}{ CanESM2 } & Mean & 1 & 1 & 7 & 1 & 1 & 9 & 5 & 23 & 1 & 2 & 5 \\
\hline & $\mathrm{SD}$ & 10 & 10 & 11 & 7 & 8 & 7 & 7 & 7 & 5 & 8 & 8 \\
\hline \multirow[t]{2}{*}{ CESM1-CAM5 } & Mean & 2 & 0 & 1 & 1 & 4 & 11 & 6 & 12 & 3 & 1 & 4 \\
\hline & SD & 7 & 5 & 4 & 8 & 9 & 14 & 8 & 4 & 7 & 5 & 7 \\
\hline \multirow[t]{2}{*}{ CSIRO-MK3.6 } & Mean & 9 & 4 & 2 & 0 & 4 & 26 & 17 & 13 & 6 & 0 & 8 \\
\hline & SD & 11 & 8 & 4 & 4 & 9 & 22 & 9 & 11 & 5 & 6 & 9 \\
\hline \multirow[t]{2}{*}{ IPSLCM5A-LR } & Mean & 1 & 6 & 3 & 2 & 5 & 9 & 6 & 18 & 5 & 1 & 6 \\
\hline & $\mathrm{SD}$ & 5 & 8 & 5 & 10 & 7 & 8 & 5 & 16 & 9 & 2 & 8 \\
\hline \multirow[t]{2}{*}{ MIROC5 } & Mean & 4 & 4 & 5 & 4 & 2 & 26 & 17 & 6 & 1 & 6 & 8 \\
\hline & SD & 8 & 10 & 5 & 11 & 6 & 4 & 13 & 4 & 5 & 2 & 7 \\
\hline
\end{tabular}


Table 4. Percentage of locations where precipitation biases lie outside the $95 \%$ confidence intervals (25-year time window)

\begin{tabular}{|c|c|c|c|c|c|c|}
\hline $\begin{array}{l}\text { GCM name and } \\
\text { number of grid } \\
\text { cells }\end{array}$ & & 1900-1924 & 1925-1949 & 1950-1974 & 1975-1999 & Avg \% \\
\hline \multirow[t]{2}{*}{ BNU-ESM } & Mean & 12 & 49 & 17 & 5 & 21 \\
\hline & SD & 1 & 42 & 22 & 3 & 17 \\
\hline \multirow[t]{2}{*}{ CanESM2 } & Mean & 1 & 9 & 19 & 6 & 9 \\
\hline & SD & 14 & 10 & 14 & 9 & 12 \\
\hline \multirow[t]{2}{*}{ CESM1-CAM5 } & Mean & 3 & 6 & 6 & 7 & 6 \\
\hline & SD & 11 & 19 & 13 & 7 & 13 \\
\hline \multirow{2}{*}{ CSIRO-MK3.6 } & Mean & 6 & 5 & 11 & 0 & 6 \\
\hline & SD & 15 & 12 & 23 & 6 & 14 \\
\hline \multirow[t]{2}{*}{ IPSL-CM5A-LR } & Mean & 2 & 9 & 20 & 5 & 9 \\
\hline & SD & 7 & 8 & 20 & 5 & 10 \\
\hline \multirow[t]{2}{*}{ MIROC5 } & Mean & 7 & 9 & 13 & 5 & 9 \\
\hline & SD & 10 & 8 & 4 & 6 & 7 \\
\hline
\end{tabular}


Table 5. Average $\%$ of grid where precipitation biases in seasonal mean exceed $95 \%$ confidence intervals.

\begin{tabular}{|l|c|c|c|c|c|c|c|c|}
\hline \multirow{2}{*}{ GCM Name } & \multicolumn{4}{|c|}{ Average of 10-year window } & \multicolumn{5}{c|}{ Average of 25-year window } \\
\cline { 2 - 9 } & Summer & Autumn & Winter & \multicolumn{1}{c|}{ Spring } & Summer & \multicolumn{1}{c|}{ Autumn } & \multicolumn{1}{c|}{ Winter } & \multicolumn{1}{c|}{ ppring } \\
\hline BNU-ESM & 8 & 7 & 5 & 8 & 5 & $\mathbf{1 1}$ & $\mathbf{1 0}$ & $\mathbf{1 1}$ \\
\hline CanESM2 & 5 & 6 & 2 & 6 & 4 & $\mathbf{9}$ & 5 & 3 \\
\hline CESM1-CAM5 & $\mathbf{7}$ & 3 & $\mathbf{6}$ & $\mathbf{7}$ & $\mathbf{8}$ & $\mathbf{6}$ & 5 & 5 \\
\hline CSIRO-MK3.6 & $\mathbf{9}$ & 4 & 4 & $\mathbf{1 3}$ & 5 & 6 & $\mathbf{8}$ & 6 \\
\hline IPSL-CM5A-LR & 5 & 6 & 7 & 6 & 7 & 7 & $\mathbf{9}$ & 7 \\
\hline MIROC5 & $\mathbf{7}$ & 5 & $\mathbf{7}$ & $\mathbf{9}$ & $\mathbf{8}$ & 6 & 6 & $\mathbf{8}$ \\
\hline
\end{tabular}

